\title{
Zeolite-Like Boron Imidazolate Frameworks (BIFs): Synthesis and Application
}

\author{
Vera I. Isaeva ${ }^{1,2, *}$, Kostantinos E. Papathanasiou ${ }^{2}$ (D) and Leonid M. Kustov ${ }^{1,2,3, *}$ \\ 1 N.D. Zelinsky Institute of Organic Chemistry, Russian Academy of Sciences, Leninsky Prospect 47, \\ 119991 Moscow, Russia \\ 2 Institute of Ecotechnology, National University of Science and Technology MISiS, Leninsky Prospect 4, \\ 119991 Moscow, Russia; k.papathanasiou@uoc.gr \\ 3 Chemistry Department, Moscow State University, Leninskie Gory 1, bldg. 3, 119992 Moscow, Russia \\ * Correspondence: sharf@ioc.ac.ru (V.I.I.); LMK@ioc.ac.ru (L.M.K.)
}

Received: 2 June 2020; Accepted: 6 July 2020; Published: 15 July 2020

\begin{abstract}
This review is devoted to discussion of the latest advances in design and applications of boron imidazolate frameworks (BIFs) that are a particular sub-family of zeolite-like metal-organic frameworks family. A special emphasis is made on nanostructured hybrid materials based on BIF matrices and their modern applications, especially in environment remediation and energy conversion.
\end{abstract}

Keywords: boron imidazolate frameworks (BIFs); zeolite-like materials; metal nanoparticles; environment remediation

\section{Introduction}

Currently, all highly ordered inorganic materials, i.e., zeolites, aluminophosphates and metalaluminophosphates (MAPO), are the "corner stones" of the numerous industrial processes of a major part of the global economy [1], such as oil refining, catalysis, adsorption, separation, food industry and detergents production [2,3]. The functional zeolite-like materials have several characteristics that determine their successful practical applications: robust three-dimensional inorganic framework, high specific surface areas and homogeneous pore distribution in size and shape. More specific exploitation of zeolitic materials depends on differences in their composition. In particular, zeolites or aluminosilicate molecular sieves have pores or channels formed by alumina and silica tetrahedra linked through oxygen bridges. It is pointed out in the numerous relevant publications that zeolite structures are comprised of $\mathrm{Si}$ and/or $\mathrm{Al}$ tetrahedral metal ions $(\mathrm{T})$ bridged by oxygen atoms (O, oxide ions) at approximately $145^{\circ} \mathrm{T}-\mathrm{O}-\mathrm{T}$ angles that are a golden standard while designing and constructing the novel practically important porous materials [4]. In turn, microporous aluminophosphate molecular sieves, denoted as $\mathrm{AlPO}_{4}-n$, are constructed of $\mathrm{AlO}_{4}{ }^{-}$and $\mathrm{PO}_{4}{ }^{+}$tetrahedral building blocks, and thus the resulting networks are neutral [5-8]. Therefore, aluminophosphate structures have a much higher degree of ionic character than those of aluminosilicate zeolites. One of the possibilities of the rational design of open $\mathrm{AlPO}_{4}-n$ frameworks is a substitution of the $\mathrm{Al}^{3+}$ tetrahedral sites by different metal ions to yield metal-containing aluminophosphate (MAPO) molecular sieves ( $\mathrm{M}=$ metal ion) [9]. The topology and pore system of the $\mathrm{AlPO}_{4}$ molecular sieves are varied in a broad range of different structure types. Some of them are analogous to several zeolites. For instance, $\mathrm{AlPO}_{4}-42, \mathrm{AlPO}_{4}-34$ and $\mathrm{AlPO}_{4}-37$ correspond to the zeolite A structure (Linde type A, LTA), chabazite structure (CHA) and faujasite structure (FAU), respectively [10].

Thanks to worldwide applications and importance of zeolites and zeolite-like materials, the search for new zeolites becomes the focus of an increased year-by-year research interest. In the course of these endeavors, considerable efforts have been devoted to the preparation of new zeolites with novel porous 
architectures and compositions. The next stage in the development of the zeolitic nanoporous materials is a discovery of metal-organic frameworks (MOFs) around twenty years ago. MOFs are a novel type of hybrid inorganic-organic matrices synthesized in the form of three-dimensional frameworks with micro/mesoporous structures [11,12]. Analogous to zeolites, MOF structures can be represented as a combination of organic polytopic molecules (linkers) and metal ions or small inorganic clusters [13,14]. In this way, an important goal in the design of the zeolite related chemistry was achieved, namely to create structures that mimic features of zeolites, first, by assembling the organic building blocks and metal ions into the zeotype framework $[15,16]$. Therefore, MOF materials are determined in some literature as metal-organic zeolites [17].

Metal-organic frameworks share a number of structural characteristics of highly ordered inorganic matrices, such as zeolites, zeolite-like molecular sieves including (silico)aluminophosphates $\left(\mathrm{ALPO}_{4}, \mathrm{SAPO}, \mathrm{MAPO}\right)$ and metal-containing silicoaluminophosphate (MSAPO) [18], namely a three-dimensional framework, high specific surface area and homogeneous distribution of pores in sizes and shapes. Along with these characteristics, MOF matrices have unique physical and chemical properties, namely the possibility of the rational design of the framework in terms of the structure, pore geometry and composition of the framework by the judicious choice of organic and inorganic building blocks, framework flexibility, as well as exceptionally high porosity, low crystal density and fully open porous structure. Moreover, functional characteristics may be further tuned by modification according to post-synthesis and in situ approaches. In particular, the incorporation of various functionalities in the metal-organic building blocks by applying the concept of secondary building units (SBUs), which have well-defined geometrical shapes leaving intact the synthesis course. Thus, the different topologies of MOF materials can be achieved by varying the arrangement of SBUs $[19,20]$.

Therefore, functional MOF materials have a higher degree of designability and adjustability for a number of specific tasks. Currently, metal-organic frameworks attract intense research attention due to their potential applications in catalysis, gas storage/separation, adsorptive water remediation, drug delivery, sensing, etc. [20-24]. In some of these applications, functional MOF materials compete successfully with zeolites, which were previously exploited.

Of particular interest are metal-organic frameworks which mimic four-connected compositional and topological features of zeolites. Zeolitic imidazolate frameworks (ZIFs) [25,26], zeolitic metal organic frameworks (ZMOFs) [17], tetrahedral imidazolate frameworks (TIFs) [27] or boron imidazolate frameworks (BIFs) [28] form a class of metal organic frameworks (MOFs) that can be considered as expanded structural analogs of zeolites [29]. They are generally built from tetrahedral metal centers bridged with ditopic ligands/linkers, where the metal-linker-metal bonding angles mimic those existing in zeolite structures, resulting in materials with extended 3D frameworks [19] analogous to zeolitic ones. Replacing the zeolitic bridging oxide ligands and the $\mathrm{Si} / \mathrm{Al}$ centers with tetrahedral transition metals not only results in a larger unit cell and pore sizes, but also has the added benefit of permitting easy functionalization and access to a range of ligand and metal combinations. Ligand identity can also affect the framework flexibility and stability, as the ligand substituents can protect the metal from a nucleophilic attack, or steric interactions between ligand substituents can form a "secondary network" that supports the framework architecture [30].

In particular, zeolite-like frameworks or zeolitic imidazolate frameworks (ZIFs) with structures similar to conventional aluminosilicate zeolites are distinguished from other numerous metal-organic frameworks. ZIFs networks with the prototypical zeolite four-connected topology (e.g., SOD, RHO, LTA, etc.) are built of imidazolate linkers with various functional substituents and metal bivalent ions. ZIF structures are built of $\mathrm{M}(\mathrm{im})_{4}(\mathrm{im}=$ imidazolate) tetrahedra constructed by the coordination between $\mathrm{M}^{2+}$ cations and im anions, where im units constitute the bridges connecting the metal centers [31,32]. The bonding angle formed by imidazolates when bridging transition metals (M-im-M) is close to the Si-O-Si bond angle $\left(145^{\circ}\right)$ in zeolites, which gives rise to many different ZIF networks with zeolite-like topological structures [33]. The representative ZIF matrices with zeolitic structures 
are shown in Figure 1. Their numerous fascinating properties provide potential utilization in a broad range of applications including gas capture and separation, sensing, catalysis, electronic devices and drug delivery [34].

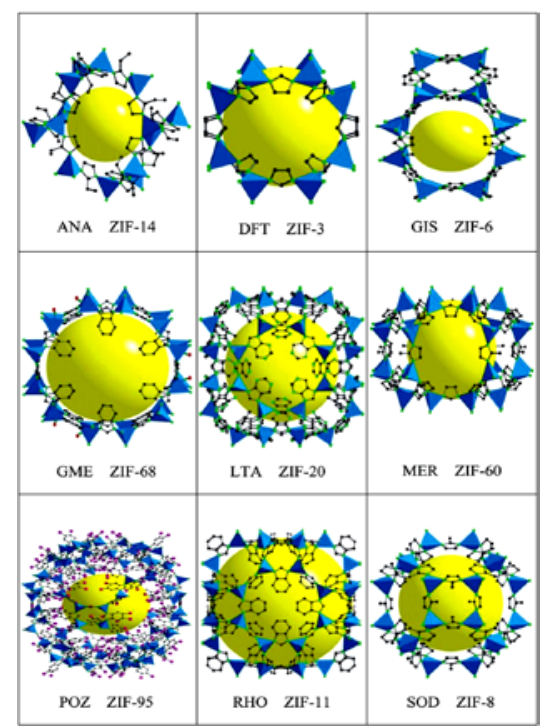

Figure 1. Representative crystal structures of ZIFs (the first three capital letters under each example stand for the zeolite structure code). Reprinted with permission from [6].

One more member of the family of zeolite-like MOF materials, which is a rather close relative to the ZIF structures, boron imidazolate frameworks (BIFs), was discovered ten years ago [15,35]. Boron imidazolate frameworks are formed by crosslinking of various pre-synthesized boron imidazolate complexes (ligands or linkers) by metal cations. In other words, zeolite-like BIF structures are based on two different tetrahedral nodes or building units, e.g., $\mathrm{B}^{3+}$ and $\mathrm{M}^{+, 2+}$, such as $\mathrm{Li}^{+}$and $\mathrm{Cu}^{+}[36,37]$. The topology of boron imidazolate frameworks is similar to other important sub-class of zeolitic materials—aluminophosphates $\left(\mathrm{AlPO}_{4}\right)$.

Thus, zeolitic imidazolate frameworks and boron imidazolate frameworks can be regarded as the genealogically close relatives, "cousins" in some sense. In particular, most of inorganic-organic hybrid ZIFs matrices and BIFs structures adopt tunable zeolite-type topologies (e.g., SOD, RHO, LTA etc.) and may have promising applications for gas storage and separation [31,35]. In this context, we intend to outline a number (the more, the better) of distinct features of BIF matrices other than those of MOF structures or even ZIF materials.

Since the basic design principles of the synthetic methodology to construct specifically topological BIFs, especially, towards the zeolitic topologies, were discussed in the review by H.-X. Zhang, which was published in 2016 [15], the authors avoid tentatively the discussion of such key aspects of the rational design of BIF structures, e.g., charge-balancing and geometry principles. This mini-review can be regarded to some extent as a "milestone" progress report, which discusses the recent advances in the field of the BIFs investigations. The special emphasis is made on the design of BIF based hybrid nanomaterials and their modern applications, i.e., environment remediation and biomedicine.

\section{Rational Construction of Boron Imidazolate Frameworks}

Currently, serious research efforts are paid to the rational design of particular BIF materials with specific zeolitic topologies with a practical importance [15]. It is pointed out [37] that design principles for BIF networks combine those applied for the creation of the classical MOF structures and covalent organic frameworks (COFs) [38,39].

As zeolite-like MOF structures, BIF matrices are composed of topologically zeo-mimetic nets based on three- or four-connected boron imidazolate ligands. Uniformly distributed 3/4-connected 
boron components that are three- or four-connected boron imidazolate linkers maintain the framework integrity [40]. According to the modular synthesis principles, the pre-synthesized three-connected $\mathrm{HB}(\mathrm{Im})_{3}{ }^{-}$tripodal ligands and four-connected $\mathrm{B}(\mathrm{Im})_{4}$ tetrahedral ligands can be used as building blocks for self-assembly of boron imidazolate frameworks mostly under solvothermal conditions. This strategy assists to a more precise rational design of the boron imidazolate frameworks with an appropriate topology needed for a specific task.

Despite the similarity of ZIFs and BIFs zeolite-like frameworks in terms of zeolite-like topology and organic linkers based on substituted imidazoles, there are some differences in their structures. ZIF structures are built of imidazolates with different substituent groups and bivalent metal ions $\left(\mathrm{M}^{2+}\right)$ (Figure 1). Boron imidazolate frameworks may be constructed of organic linkers in the form of boron substituted by imidazolates in a tetrahedral configuration (boron imidazolate complexes) and bivalent or monovalent metal ions.

In relation with the archetypic zeolite structure, to construct ZIFs, a typical strategy is the use of divalent metal cations $\left(\mathrm{Zn}^{2+}\right.$ in particular) and imidazolate ligands ( $\left.\mathrm{Im}\right)$ with different substituents to replace $\mathrm{Si}^{4+}\left(\mathrm{Al}^{3+}\right)$ and $\mathrm{O}^{2-}$ in zeolites, respectively [38]. Similar to how $\mathrm{Al}^{3+}$ and $\mathrm{P}^{5+}$ in microporous $\mathrm{AlPO}_{4}$ matrices formally replace $\mathrm{Si}^{4+}$ in $\mathrm{SiO}_{2}$ units of classical zeolites, so do $\mathrm{M}^{+}$and $\mathrm{M}^{2+}$ and $\mathrm{B}^{3+}$ nodes in BIF networks replace $\mathrm{M}^{2+}(\mathrm{M}=\mathrm{Zn}, \mathrm{Cd}, \mathrm{Co}$, etc.) in ZIF structures [15,37] (Scheme 1).

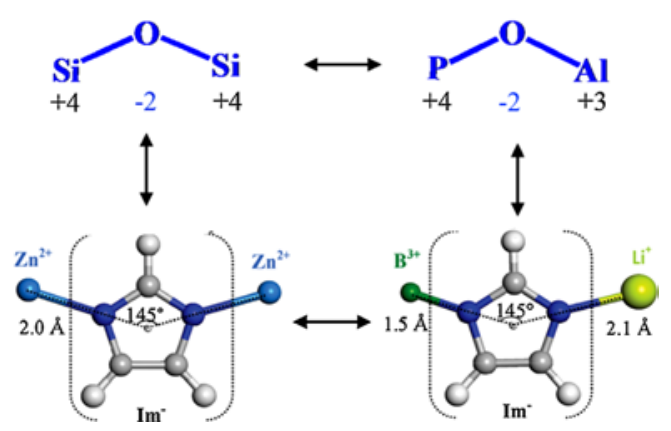

Scheme 1. The similarity of coordination geometries between tetrahedral metalimidazolate and aluminosilicates. ZIFs (left) versus BIFs (right) in terms of metal-imidazole-metal angles and distances. Reprinted with permission from [15].

All BIF materials contain the ultra-lightweight element B constituting a strong covalent bond (B-N) in the three- or four-connected boron imidazolate ligands (Scheme 2). These distinct features of the boron imidazolate frameworks assist to their rational design for the specific task. Note that the use of $\mathrm{B}^{3+}$ as the framework polyhedral node is very attractive from practical point of view because boron is one of the lightest elements allowing to decrease the density of the produced BIF matrix [36]. For instance, some BIF materials, namely lithium-boron imidazolates, are regarded as promising materials designated for hydrogen storage.

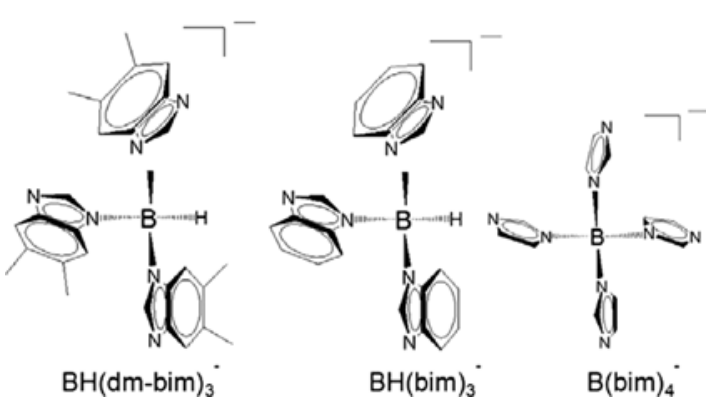

Scheme 2. The pre-synthesized boron imidazolate ligands for the construction of different BIF structures. Reprinted with permission from [15]. 
It would be interesting to highlight the differences between tetradentate and tridentate boron imidazolate linkers in terms of their capabilities to construct the boron imidazolate frameworks. In particular, the most often reported BIF structures (along with ZIF frameworks) feature four-connected zeotype topologies with the tetrahedral coordination mode of metal centers (metal ions). Accordingly, the tetradentate boron imidazolate ligands link tetrahedral metal centers into boron imidazolate frameworks with several zeotype topologies [28]. In turn, selected tridentate boron imidazolate ligands in a combination, in some particular cases with additional or auxiliary carboxylate ligands, link metal centers with the formation of the interrupted zeolite structure [41]. The zeolitic boron imidazolate frameworks designed by this approach exhibit topologies, which associate with tailoring the pore size and shape adjusted for specific applications [42].

In particular, the assembly of three-connected $\mathrm{HB}(\mathrm{im})_{3}$ linkers and three-connected metal centers results in the formation of BIF materials with unique interrupted zeolite A (LTA) or ATN-type frameworks [41]. A surplus is that $\mathrm{HB}(\mathrm{im})_{3}{ }^{-}$linkers have the $\mathrm{B}-\mathrm{H}$ bond, which can contribute to hydrogen adsorption [35]. For instance, the use of the pre-synthesized $\mathrm{BH}(\mathrm{mim})_{3}{ }^{-}$linkers for the BIF material construction allows one to create the boron imidazolate frameworks BIF-20 and BIF-21 with interrupted zeolite LTA and ATN topologies, respectively (Table 1) [41].

Table 1. Some practically relevant BIF structures.

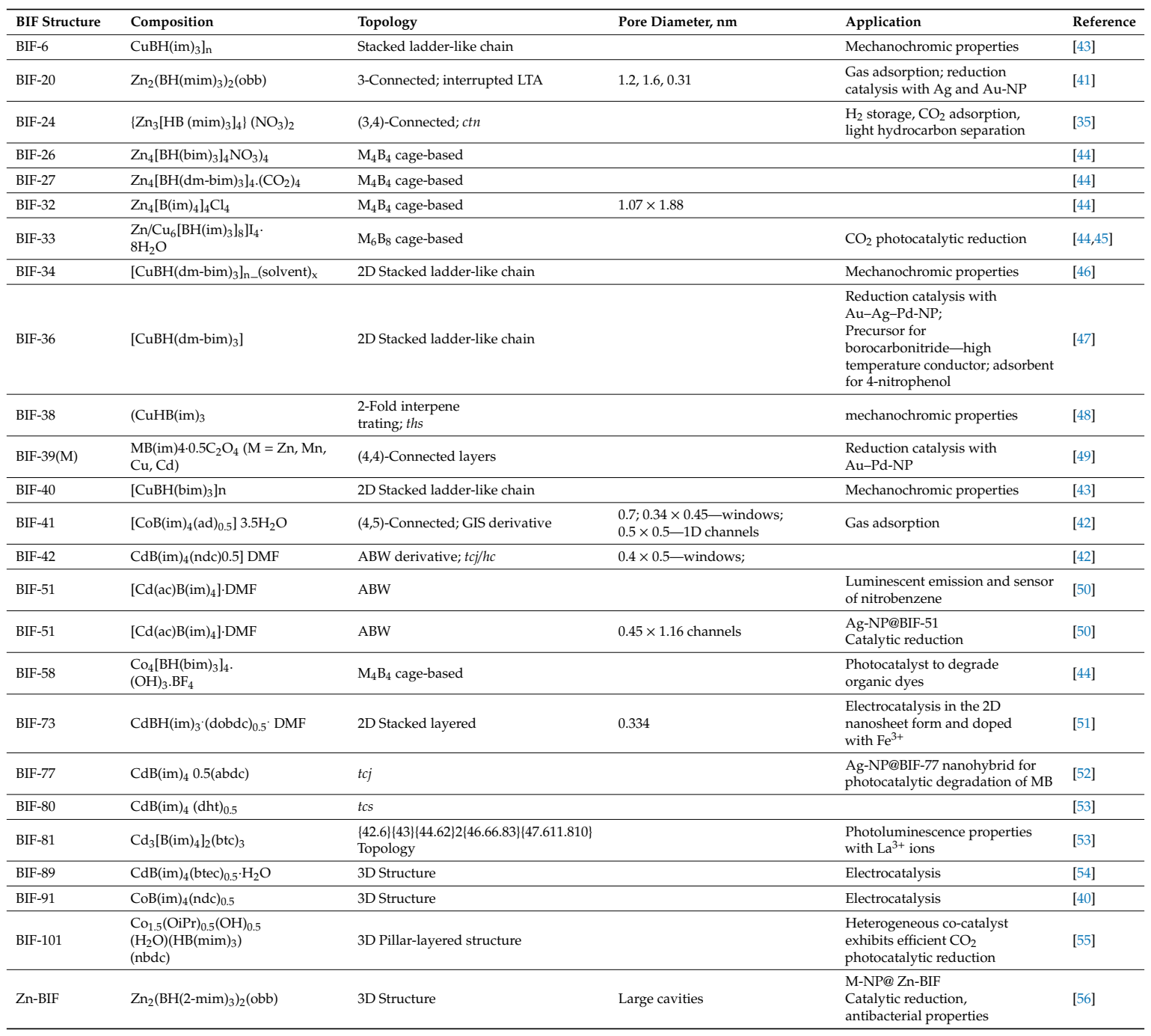

An obvious method for the construction of the mixed $(3,4)$-connected boron imidazolate framework is an integration of three-connected $\mathrm{HB}(\mathrm{im})_{3}{ }^{-}$linkers with tetrahedral metal centers as $\mathrm{M}^{2+}$ ions [28]. 
An example is the boron imidazolate framework BIF-24 (Table 1) comprising (3,4)-connected nets with a rare $c t n$ energetically stable topology constructed from the $\mathrm{HB}(\mathrm{mim})_{3}{ }^{-}$ligands and tetrahedral $\mathrm{Zn}^{2+}$ centers [35].

Abbreviations used in the table: abdc, 2-aminobenzene-1,4-dicarboxylate; ad, adipate; btc, benzene-1,3,5-tricarboxylate; bim, benzimidazolate; bipy, 2,2'-bipyridine; btec, benzene-1,2,4,5tetracarboxylate; dht, dihydroxyterephthalate (dihydroxybenzene-1,4-dicarboxylate); dm-bim, 5,6-dimethylbenzimidazolate; DMF, N,N-dimethylformamide); dobdc, dihydroxybenzene1,4-dicarboxylate; im, imidazolate, $\mathrm{MB}$, methylene blue; mim=2-methylimidazolate; nbdc, 2-nitro-benzene-1,4-dicarboxylate; ndc, 2,6-naphthalenedicarboxylate; NP, nanoparticles; obb, 4,4'-oxybis(benzoate); OiPr, isopropyl alcohol.

This BIF-24 material may have a potential application as a promising adsorbent for some gases (its adsorption properties is discussed in the next section).

Another efficient way to construct the boron imidazolate frameworks with mixed connectivity is employing mixed linkers strategy for the design of these zeolite-like networks that is not restricted to purely tetrahedral nets. Thus, a distinct way for constructing the zeolite-like BIF materials, including networks with interrupted zeolite structures, is to replace partially the imidazolate linkers in boron imidazolate frameworks for dicarboxylate ones [35,53].

The BIF-20 matrix displaying a neutral interrupted zeolite LTA structure (Table 1) mentioned above was prepared using tripodal $\mathrm{BH}(\mathrm{mim})_{3}{ }^{-}$linkers and auxiliary obb linkers. This material is formed as an unusual tetrahedral framework with debonded $\alpha$ and $\beta$ cages as large cavities [41]. It is well known that zeolite A (LTA) is a very popular member of zeolite family because of its large-scale industrial applications [57]. A construction of a BIF material with Zeolite A topology that is a typical four-connected tetrahedral framework with a lower connectivity may lead to an interesting open architecture with an expanded ring size and enhanced functional characteristics for diverse potential applications. Note that some potential application fields for the BIF-20 material are discussed in the next sections.

Using the mixed linker is an efficient strategy for the construction of typical tetrahedral zeolite BIF structures containing two kinds of tetrahedral centers, e.g., B (boron) and four-connected $\mathrm{M}$ cations (e.g., $\mathrm{Li}^{+}, \mathrm{Cu}^{+}, \mathrm{Co}^{2+}$ and $\mathrm{Zn}^{2+}$ ), which are connected by imidazolate ligands and auxiliary linkers. This strategy is based on the principle of charge balancing for the final boron imidazolate framework. For instance, a series of neutral BIF matrices including the zeolite type structures (e.g., ACO and ABW) was synthesized starting from pre-synthesized four-connected boron imidazolate ligands $\left(\mathrm{B}(\mathrm{im})_{4}\right)$ and $\mathrm{ML}^{+}\left(\mathrm{L}=\mathrm{CH}_{3} \mathrm{COO}^{-}, \mathrm{Br}^{-}\right)$building blocks based on tetrahedral $\mathrm{M}^{2+}$ cations and uni-charged negative auxiliary carboxylate ligands, e.g., oxalate, acetate, bromide) and $\mathrm{M}^{2+}(\mathrm{M}=\mathrm{Cu}, \mathrm{Zn}, \mathrm{Mn}$, and $\mathrm{Cd})$ ions $[37,50]$. Thus, two zeolitic BIF materials (BIF-22 and BIF-23) were obtained by using octahedral divalent metal centers [37].

In some cases, supplementary linkers based on organic acids allow one to manipulate with metal node connectivity in the resulted boron imidazolate framework. This is a way to the pore space partition in zeotype frameworks to which BIF matrices belong. For instance, a zeolitic boron imidazolate framework, BIF-51, with ABW topology was constructed using pre-synthesized Bim $4^{-}$ ligands and $\left[\mathrm{Cd}\left(\mathrm{CH}_{3} \mathrm{COO}\right)\right]^{-}$building blocks (Table 1) [50]. The strategy to form the tetrahedral metal node involves reducing six-coordinate to four-connectivity by using acetate ion as a chelating ligand. Thus, a +1 charged $\left[\mathrm{M}^{2+}(\mathrm{ac})^{-}\right]^{+}(\mathrm{M} 1 / 4=$ transition metal; $\mathrm{ac}=$ acetate $)$ unit matching to $\mathrm{a}-1$ charged $\mathrm{Bim}_{4}{ }^{-}$unit assembled to four-connected zeolitic frameworks (Scheme 3) [49]. An example of this strategy is the BIF-51 matrix of the ABW-type, which can be used as a sensor of nitrobenzene due to luminescent properties [50]. 


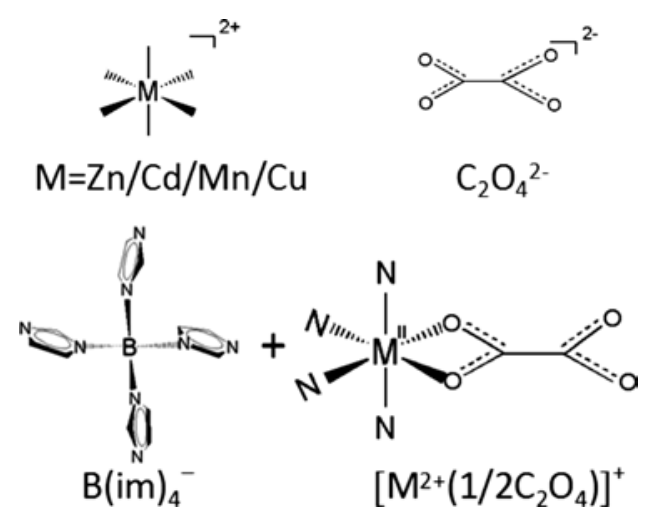

Scheme 3. Self-assembly of neutral BIF structures using $\mathrm{B}(\mathrm{im})_{4}{ }^{-}$and $\left[\mathrm{M}^{2+}\left(1 / 2 \mathrm{C}_{2} \mathrm{O}_{4}{ }^{2-}\right)\right]^{+}$building blocks. Reprinted with permission from [49].

An appropriate usage of the mixed linker approach involving using pre-synthesized boron imidazolate linkers in a combination with polycarboxylate ligands for the construction of the BIF materials may result in the pore partition for a number of structures. In particular, replacing a chelating ligand such as acetate by a bridging dicarboxylate ligand results in cross-linking of one linker with each other via metal coordination centers. In turn, it results in the pore space partition in the zeolitic network (Figure 2) [42,58]. Thus, this approach results in generating pore space partition in zeolitic boron imidazolate frameworks via adding surplus linkers.

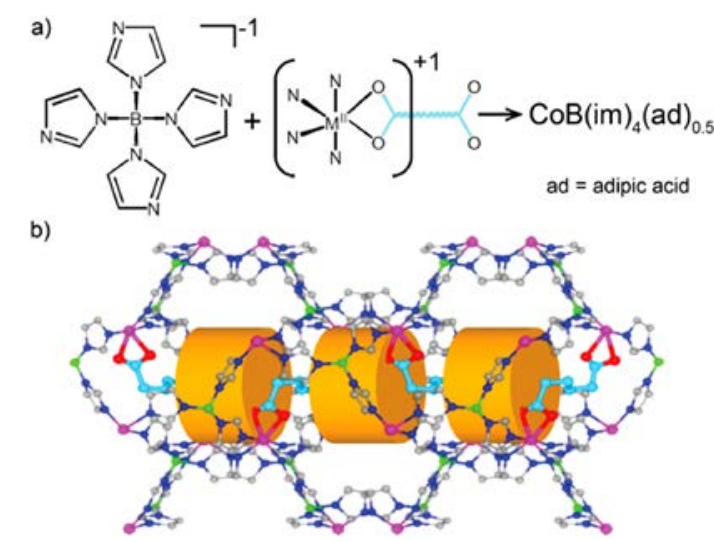

Figure 2. (a) Strategy for the synthesis of BIFs showing pore space partition; and (b) GIS-type framework of the BIF-41 material. Reprinted with permission from [6].

The practically important pore space partition in zeolite-like nets of BIF matrices can be also provided by using bridging dicarboxylate ligands. This strategy was used for the construction of $(4,5)$-connected zeolitic frameworks by employing the tetradentate $\mathrm{B}(\mathrm{im})_{4}$ ligands and linear dicarboxylate linkers. According to this approach, a GIS-type boron imidazolate framework BIF-41 and an ABW-type BIF-42 (Table 1) were constructed using different dicarboxylate linkers, i.e., adipate and 2,6-naphthalenedicarboxylate [42].

In the BIF-41 structure, the $\mathrm{B}(\mathrm{im})_{4}$ ligands connect the $\mathrm{Co}^{2+}$ nodes into a typical four-connected GIS-type framework, while the bridging adipic acid ligands act as additional bonds to link two adjacent $\mathrm{Co}$ centers. The Co-B connectivity in the BIF- 41 structure features a previously unknown (4, 5)-connected net, which is derived from the zeolite of GIS topology by adding one linker for each Co center.

Note that GIS topology in the BIF-41 structure differs from the classical one. Generally, the net with GIS topology consists of channels with eight-ring openings in two directions and these channels intersect each other to form a three-dimensional channel system [42]. On the contrary, the BIF-41 matrix 
contains a 1D channel system with the channel window size about $5 \times 5 \AA$, because the channel in the other direction has been partitioned into multiple domains by the bridging dicarboxylate (namely, adipate) ligands. Thus, in the BIF-41 structure, a distorted GIS-cage with the pore size about $0.7 \mathrm{~nm}$ in diameter is formed.

As mentioned above, this strategy can be extended to other BIF structures with zeolite-like topology. Thus, another ABW-type boron imidazolate framework, BIF-42, with pore space partition was constructed. The distinct topologies of the BIF-41 and BIF-42 matrices may be raised from the use of different dicarboxylate linkers, ad for the BIF- 41 structure and ndc for the BIF- 42 framework (Table 1). The authors of [42] highlighted the peculiarities of the mechanism of the formation of the zeolite-like BIF materials. This templating mechanism is in remarkable contrast with the mechanism based on the link-link interactions in ZIF matrices and the structure directing agents in zeolites.

Similar to the BIF- 41 structure, each tetrahedral Cd ${ }^{2+}$ center in the BIF- 42 structure adopts $\mathrm{CdN}_{4} \mathrm{O}_{2}$ distorted octahedral coordination geometry and is coordinated by four nitrogen atoms from the $\mathrm{B}(\mathrm{im})_{4}$ ligands and two chelate carboxylate oxygen atoms from the bridging ndc ligand. However, the $\mathrm{B}(\mathrm{im})_{4}{ }^{-}$ linkers connect the $\mathrm{Cd}^{2+}$ nodes into a typical four-connected ABW-type framework, in which the ndc linkers connecting two adjacent $\mathrm{Cd}^{2+}$ centers cause the pore space partition in the BIF-42 network. The pore space partition patterns for the BIF- 41 and BIF- 42 matrices are also found. The redundant ndc linkers in the BIF-42 structure partition one large channel into two small channels occupied by disordered DMF molecules and the windows size decreased from $10 \times 5$ to $4 \times 5 \AA$. The Cd-B connectivity in the BIF- 42 matrix features a $(4,5)$-connected net with the $t c j / h c$ topology, which is derived from the zeolite ABW topology.

The separation of the relatively large free space inside the pores may contribute in some specific applications, e.g., small molecules adsorption such as $\mathrm{CO}_{2}$, for the $\mathrm{BIF}$ functional materials. An example is a design and synthesis of two BIF matrices with ABW and GIS topologies [52]. In this way, the BIF-77 structure with GIS topology (Table 1) was constructed. $\mathrm{Cd}^{2+}$ nodes are connected via B(im) $)_{4}$ and 2-abdc linkers connecting the $\mathrm{Cd}$ centers with formation of an open 3D framework with accessible pore volume about $23.2 \%$. The authors suggest that, without the 2-abdc ligands, the $\mathrm{Cd}^{2+}$ and $\mathrm{B}^{3+}$ coordination centers would be solely linked by the im ligands into a four-connected network with $h c p$ topology. Under conditions of the presence of the 2-abdc ligands in the structure, the framework displays a $t c j$ topology. Thus, this work provides an efficient route towards the construction of the functional BIFs materials with different substituted groups in the supplementary organic linkers.

Generally, the use of the mixed linkers strategy for the BIF structure construction may result in enrichment of a number of useful properties, e.g., photoluminescence. For instance, $\mathrm{Cd}^{2+}$ nodes, phenylene polycarboxylate and $\mathrm{B}(\mathrm{im})_{4}$ linkers were used for constructing two boron imidazolate frameworks, i.e., neutral BIF- 80 and anionic BIF- 81 frameworks (Table 1) with remarkable luminescence properties [53].

An interesting example of the BIF structure based on metal centers with two different coordination environments is the boron imidazolate framework BIF-95, which is based on the in situ generated +1 and 0 mixed charged metal nodes, such as $\mathrm{Zn}^{2+}$ and $\mathrm{Zn}^{+}$ions and 3D pillared-layer structure [59]. It was suggested that this is a useful way for the construction of neutral BIF structures by manipulating with charges of the metal ions.

A particularly promising approach for the creation of the extended BIF networks involves using the pre-synthesized metal-organic cages (MOCs) as building blocks. MOCs or metal organic polyhedrons (MOPs) according to Yaghi [60,61] feature some favorable properties, such as chemical stability in acidic and basic media and solubility, confined voids and particular structures. Therefore, metal-organic cages may have potential applications in molecular recognition and catalysis $[62,63]$. The typical MOC structure is presented in Figure 3. 

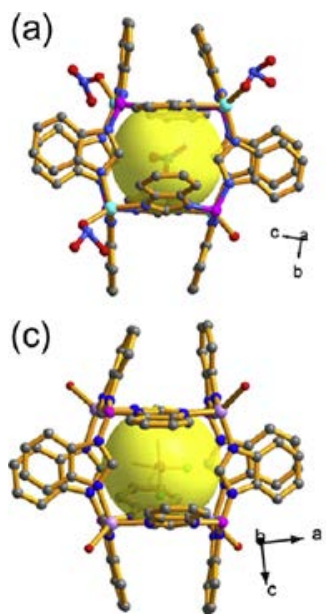

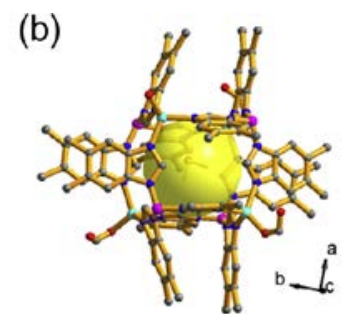

(d)

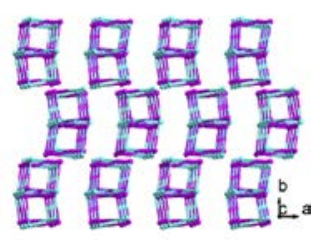

Figure 3. (a) The cubic cage in the BIF-26 framework. (b) The cubic cage in the BIF-27 framework. (c) The cubic cage in the BIF-58 framework. (d) The packing of cages in the BIF-27 framework. Color codes: Zn, pale blue; Co, lavender; B, purple; O, red; C, gray; N, blue. Partial H atoms are omitted for clarity. Reprinted with permission from [44].

The preparation of the BIF structures using MOCs is based on cage-based self-assembly for some zeolites and other porous frameworks. Actually, the cubic $a$-cage is a well-known secondary building unit in many zeolite structures [58]. The discrete MOCs are often considered as ideal building blocks for the construction of extended porous metal organic frameworks [64]. In this field, particular attention is paid to the single-crystal transformation of MOGs to extended open metal-organic frameworks [65]. Note that a common way for creating the discrete cubic boron imidazolate cages involves divalent metal centers with tetrahedral coordination geometry [66,67].

In particular, the solubility properties allow one to use MOC structures for the construction of BIF materials under solvothermal synthesis conditions involving generally heating of the reagent's solution. Note that the common strategy for the BIFs synthesis involves using the pre-synthesized $\mathrm{BIm}_{4}$ and $\mathrm{HBim}_{3}$ linkers. Therefore, the possible complications arising from side reactions because of B-H bond lability in $\mathrm{HBim}_{3}$ linkers could prevent the appropriate BIF structure construction. Using pre-synthesized MOCs as building blocks may prevent this hindrance. This strategy involves self-assembly of discrete metal boron imidazolate cages comprising tetradentate boron imidazolate ligands in two-dimensional BIF frameworks. However, despite this approach efficiency, there are only limited examples of its use for the BIF construction. An example is the formation of zeolite type BIF matrices with $a$ or $b$ cage substructures prepared using a cubic cage $\left(\mathrm{M}_{4} \mathrm{~L}_{4}\right)$ and two dodecahedral cages $\left(\mathrm{M}_{6} \mathrm{~L}_{8}\right)$ with $\mathrm{Zn}^{2+}$ and $\mathrm{Cu}^{2+}$ ions ( $\mathrm{L}=$ imidazolate ligand) according to cage self-assembly [44]. The principle of self-assembly of the dodecahedral cage $\left(\mathrm{M}_{6} \mathrm{~L}_{8}\right)$ is shown in Figure 4 [45].

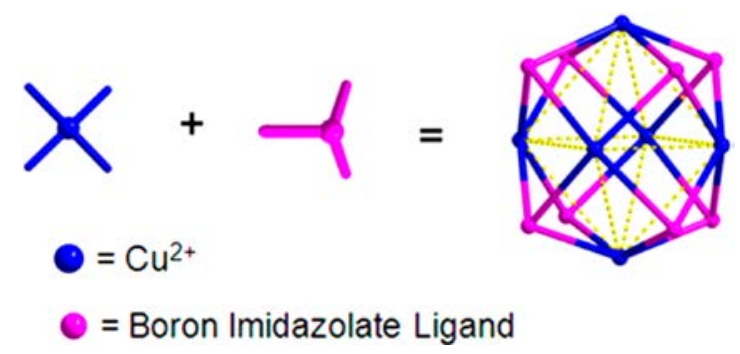

Figure 4. Principle of self-assembly of the dodecahedral cage $\left(\mathrm{M}_{6} \mathrm{~L}_{8}\right)$. Reprinted with permission from [45].

Following the strategy of the segmented cages technology in order to extend the cubic cage structure to an open BIF framework, tetradentate boron imidazolate ligands were applied for replacing 
tridentate boron imidazolate ligands. In this way, tetradentate boron imidazolate ions not only can act as cage ligands but also extend cages to frameworks serving as bridge linkers. The typical isolated boron imidazolate cage $\left(\mathrm{M}_{4} \mathrm{~L}_{4}\right)$ was designed by applying the tetrahedral $\mathrm{Zn}$ (II) center and tridentate boron imidazolate ligands. For the classical cubic cage, the tetrahedral metal center is formed by $\mathrm{Zn}^{2+}$ or $\mathrm{Co}^{2+}$ ions in a combination with different tridentate boron imidazolate ligands. Following this methodology, cubic cages were constructed using tridentate boron imidazolate ligands for further linking tetrahedral metal centers $\mathrm{Zn}^{2+}$ and $\mathrm{Co}^{2+}$ in the designed BIF framework.

The self-assembly of tridentate boron imidazolate ligands and tetrahedral coordination centers under solvothermal conditions was applied for the formation of extended porous boron imidazolate frameworks from the metal boron imidazolate cages. Tetradentate boron imidazolate ligands in the cage impart the additional connectivity, which is required for self-assembly of boron imidazolate cages into boron imidazolate frameworks.

Following this strategy determined as segmented cage technology, three cage-based boron imidazolate compounds (BIF-26/27/58) and a boron imidazolate framework (BIF-32) were synthesized (Figures 3 and 5) [44]. In this way, the $\mathrm{BH}(\mathrm{bim})_{3}{ }^{-}$(bim = benzimidazolate) ligands and $\mathrm{BH}(\mathrm{dm}-\mathrm{bim})_{3}{ }^{-}$ (dm-bim = 5, 6-dimethylbenzimidazolate) ligands were used to synthesize BIF-26, BIF-58 and BIF-27 matrices, respectively (Table 1). According to a structural study, each cubic cage in the BIF-26 and BIF-27 structures comprises four $\mathrm{Zn}^{2+}$ ions and four boron imidazolate ligands (Figure 3), where the $\mathrm{Zn}^{2+}$ and $\mathrm{B}^{3+}$ ions were linked by benzimidazolate and dimethylbenzimidazolate building blocks, respectively. In turn, the boron imidazolate framework BIF-58 is constructed of four $\mathrm{Co}^{2+}$ ions and four $\mathrm{HB}(\text { bim })_{3}{ }^{-}$ligands serving as cubic cages.

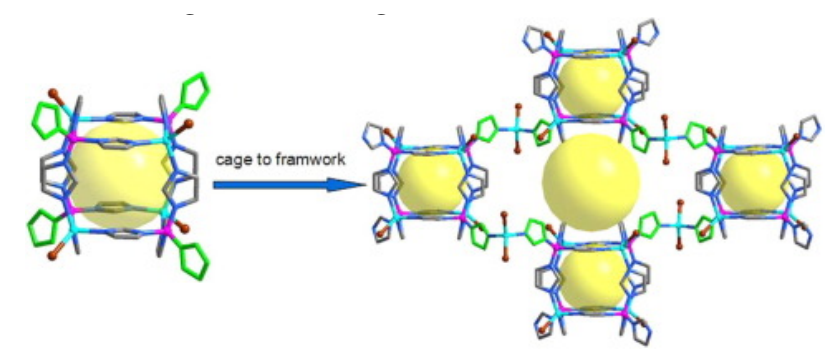

Figure 5. The illustration of the 3D BIF structure self-assembly according to the segmented cage technology. Reprinted with permission from [44].

An example of a self-assembly of $\mathrm{Zn}^{2+}$ boron imidazolate cages in a combination with inorganic $\mathrm{I}^{-}$ anions is the formation of the porous BIF-33 framework [44]. For this purpose, the following discrete structures of cages were utilized: (1) three coordination sites of tetrahedral Zn centers were coordinated by the boron imidazolate ligands, while the fourth one was linked with a special anion or guest molecule; and (2) the isolated M6L8 cages were linked by a bridging linker $\mathrm{I}^{-}$. Thus, these cubic cages may be assembled in the high-dimensional porous frameworks by particular linkers connecting the $\mathrm{Zn}^{2+}$ nodes.

Another approach is to insert directly an additional connectivity to the formed boron imidazolate framework by applying the tetradentate boron imidazolate ligands [44]. Because tetradentate boron imidazolate ligands are used, the fourth imidazolate group may connect the formed cage sub-structures into extended frameworks. The BIF-32 framework with the cubic cage sub-structure (Table 1) was synthesized by using tetradentate $\mathrm{B}(\mathrm{im})_{4}{ }^{-}$ligands ( $\mathrm{im}=$ imidazolate). An example is the self-assembly of the metal boron imidazolate cages involving tridentate boron imidazolate ligands and tetrahedral $\mathrm{Zn}^{2+}$ center into extended porous boron imidazolate frameworks under solvothermal conditions. The BIF-32 structure is a 2D framework with the $\mathrm{ZnBH}(\mathrm{im})_{4}$ cage sub-structure. In the BIF-32 material, four $\mathrm{B}(\mathrm{im})_{4}{ }^{-}$ligands connect four $\mathrm{Zn}^{2+}$ ions to form the cubic $\mathrm{Zn}_{4}\left[\mathrm{~B}(\mathrm{im})_{4}\right]_{4} \mathrm{Cl}_{4}$ cage with four imidazolate groups. Furthermore, these imidazolate groups are linked together by the $\mathrm{ZnCl}_{2}$ units, resulting in the formation of a $2 \mathrm{D}$ framework comprising cubic cages. It is interesting that the coordination linkage 
between four adjacent cubic cages generates additional porous space with dimension of $10.7-18.8 \AA^{2}$ in the 2D structure.

By exploring this method for the BIF materials construction, it was found that the functional group of imidazole in boron imidazolate ligands impact on the formation of the boron imidazolate cages and boron imidazolate frameworks on their basis. The cage-based BIF materials designed in this way may have promising potential applications like BIF-58 matrix, which can act as the photocatalyst to degrade organic dyes.

At the end of this section, it would be useful to outline some peculiarities of the two-step synthesis strategy for BIF materials in comparison to the ZIFs structures. First, the predictability of the BIF synthesis is worth noting. To date, over one hundred different metal-ligand ZIF compositions have been realized, adopting over sixty different tetrahedral topological variants of the framework [26]. Normally, ZIF materials along with other MOF structures can be synthesized by one-step self-assembly approach. Note that, in some cases, syntheses of ZIF materials lacks reproducibility and yields a number of different topological forms (i.e., framework polymorphs, once emptied) along with some side-products from the same set of starting materials and under similar reaction conditions [15]. Moreover, under the chosen reaction conditions, the product distributions can often change over time, further complicating the synthesis $[68,69]$.

Contrary to the ZIF structures, BIF materials can be synthesized with two-step synthetic strategy. These boron imidazolate ligands are synthesized prior to the self-assembly process and then they are linked by tetrahedral metal cations. Furthermore, with the two-step synthetic strategy, the connectivity of boron imidazolate ligands can be controlled through the first-step chemical synthesis. As a result, both four-connected tetrahedral $\mathrm{B}(\mathrm{im})^{4-}$ ligands and three-connected tetrahedral $\mathrm{HB}(\mathrm{im})_{3}{ }^{-}$ligands can be readily synthesized prior to solvothermal assembly, thus further increasing the diversity of materials accessible. The strategy affords materials with not only the typical four-connected zeolitic topologies, but also other types of nets. Therefore, the topologically interrupted BIFs were developed with three-connected nodes, which remain a synthetic challenge following the one-pot hydro(solvo)thermal synthesis method for the preparation of ZIF materials [15,27].

As to synthesis routes, ZIF structures can be obtained by using a broad variety of the preparation techniques, e.g., classical solvothermal procedure, MW-assisted method, mechanochemical procedure, ultrasound synthesis, RT method and some others. On the contrary, the most established way for BIF materials synthesis involves heating of the preliminarily synthesized boron imidazolate complex and an appropriate metal salt in polar solvents or in mixed solvent systems $\left(\mathrm{H}_{2} \mathrm{O}\right.$, isopropyl alcohol and DMF) under solvothermal conditions, as a rule, for tens of hours or even for a few days. Thus, the authors believe that the development of alternative fast and available method for the second stage of BIF materials synthesis is highly demanded.

\section{Potential Applications for the BIF Materials}

It is postulated in relevant contemporary reviews and experimental papers that metal-organic frameworks have significant potential for the practical application in the fields, somewhat classical, such as heterogeneous catalysis [20], gas separations and storage [70], biomedicine and molecular recognition [71].

For the BIF matrices belonging to the MOF family and discovered a decade later than metal-organic frameworks, the potential application fields are still searched and studied. Note that in the relevant research reports, a particular attention is paid to the search of the distinct application fields for the functional BIF materials that differ them from other members of the MOF family. In this context, it would be helpful to consider the remarkable characteristics of the BIF materials that defined their application fields. In this review, we would like to outline novel application fields for BIF materials that appear after the publication of the review by Zhang [15].

Moreover, it would be interesting to outline the differences and compare the application fields for zeolitic imidazolate frameworks and boron imidazolate frameworks that are both typical 
zeolite-like metal-organic frameworks taking into account some similarities in their physico-chemical characteristics [53]. In particular, ZIF materials are intensively exploited in gas separations [72,73], $\mathrm{CO}_{2}$ capture [74], heterogeneous catalysis [75] and biomedicine [76].

In turn, to date, the proposed application fields for boron imidazolate frameworks are also catalysis, including $\mathrm{CO}_{2}$ catalytic reduction, gas storage and separation, photocatalysis, electrocatalysis, hydrogen storage, $\mathrm{CO}_{2}$ capture and sensing [57]. In this context, the BIF structures with topology that is important from practical point of view are in the scope of an increased interest. In this section, we consider the particular characteristics of BIF structures allowing one to use them for solving the practical tasks.

\subsection{Gas Adsorption and Separation}

As mentioned in the previous section, tripodal $\mathrm{BH}(\mathrm{im})_{3}{ }^{-}$linkers in the boron imidazolate frameworks may enhance adsorption characteristics of the BIF adsorbents containing them in respect of some gases. The adsorption characteristics of some BIF matrices are presented in Table 2. For instance, due to a high density of B-H bonds distributed homogeneously in the BIF-20 matrix, this material exhibits a $\mathrm{H}_{2}$ uptake capacity as high as $1.43 \mathrm{wt} . \%(77 \mathrm{~K}, 1 \mathrm{~atm})$ (Table 2) [77]. This value is almost equal to that measured for the zeolitic imidazolate framework ZIF-11 and is significantly higher than that of LTA-type zeolitic imidazolate framework ZIF-20 (1.1 wt.\%). The initial isosteric heat of $\mathrm{H}_{2}$ adsorption value Qst calculated for the BIF-20 material is $6.1 \mathrm{~kJ} \mathrm{~mol}^{-1}$, which is comparable with other porous materials like ZIF matrices with LTA topology (e.g., ZIF-76) [78].

Besides B-H bonds and favorable topology, the BIF porous structure may also impact on the gas sorption behavior. For instance, small windows and large inner cages in the BIF-20 framework results in its particular capabilities for the $\mathrm{N}_{2}$ and $\mathrm{CO}_{2}$ sorption [41]. The $\mathrm{CO}_{2}$ uptake values measured for the BIF-20 material are $53.9 \mathrm{~cm}^{3} / \mathrm{g}(2.41 \mathrm{mmol} / \mathrm{g})$ at $273 \mathrm{~K}$ and $34.8 \mathrm{~cm}^{3} / \mathrm{g}(1.55 \mathrm{mmol} / \mathrm{g})$ at $298 \mathrm{~K}$ (Table 2). These values are comparable to those measured for ZIF-8 and ZIF-100 adsorbents [31]. Additionally, the BIF-20 matrix shows a high selectivity in the $\mathrm{CO}_{2} / \mathrm{N}_{2}$ separation under ambient conditions.

Next example of the relevance of the particular BIF structure and topology to the important gas sorption properties is a $c t n$-type boron imidazolate framework BIF-24 (Table 1) composed of $\mathrm{HB}(\mathrm{mim})_{3}{ }^{-}$ ligands and tetrahedral $\mathrm{Zn}^{2+}$ centers [35]. Note that this $\mathrm{ctn}$ topology is rather rare for BIF structures and is observed mostly in other zeolite-like materials, such as tetrahedral tetrazolate frameworks (TTFs) [79] The free accessible volume in the BIF-24 matrix is $4044.3 \mathrm{~A}^{3}$ per unit cell, and the pore volume ratio is $47.0 \%$ calculated with the PLATON program. The BIF-24 matrix shows the hydrogen uptake capacity of $1.88 \mathrm{wt} . \%$ or $211.6 \mathrm{~cm}^{3} \mathrm{~g}^{-1}(77 \mathrm{~K}, 1 \mathrm{~atm}$ ) (Table 2). This value is higher than that measured for other BIF materials including the BIF-20 adsorbent. At a zero coverage, the enthalpy of $\mathrm{H}_{2}$ adsorption for BIF-24 is $6.8 \mathrm{kJmol}^{-1}$, which is comparable to the reported Qst values measured for the HKUST-1, PCN-6 and PCN-26 metal-organic frameworks with phenylenecarboxylate linkers. The fraction of the pore volume filled by liquid $\mathrm{H}_{2}\left(1 \mathrm{H}_{2}=0.0708 \mathrm{~cm}^{3} \mathrm{~g}^{-1}\right)$ calculated for the BIF-24 matrix is $65.4 \%(77 \mathrm{~K}, 1 \mathrm{~atm})$, which is comparable to this parameter value obtained for the IRMOF-74 framework (64.1\%) [80]. 
Table 2. Uptake values for the selected BIF structures.

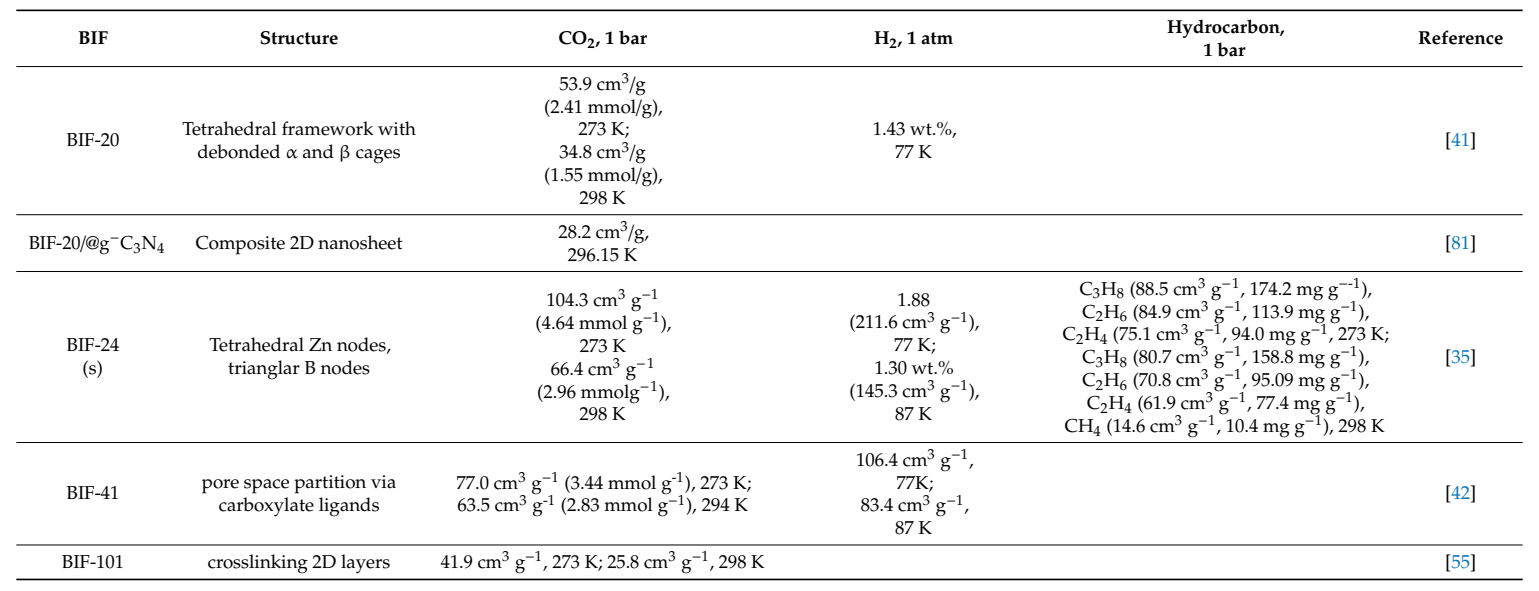

The $\mathrm{CO}_{2}$ uptake value measured for the BIF-24 material is $104.3 \mathrm{~cm}^{3} \mathrm{~g}^{-1}$ or $4.64 \mathrm{mmol} \mathrm{g}^{-1}$ (273 K) and $66.4 \mathrm{~cm}^{3} \mathrm{~g}^{-1}$ or $2.96 \mathrm{mmol} \mathrm{g}^{-1}(298 \mathrm{~K})$ (Table 2). This value is much higher than that demonstrated by other BIF materials studied in $\mathrm{CO}_{2}$ adsorption. Moreover, this $\mathrm{CO}_{2}$ uptake value surpasses the values measured for most ZIF matrices with enhanced specific adsorption properties relevant to carbon dioxide, for instance, the ZIF-69 material showing the $\mathrm{CO}_{2}$ uptake capacity of $70 \mathrm{~cm}^{3} \mathrm{~g}^{-1}(273 \mathrm{~K}$, 1 bar) [33].

High selectivities for the adsorption of $\mathrm{CO}_{2}$ or $\mathrm{C}_{2}$ and $\mathrm{C}_{3}$ hydrocarbons over $\mathrm{CH}_{4}(\mathrm{RT})$ was observed for the BIF-24 adsorbent (Table 2) [35]. The ideal adsorption $\mathrm{CO}_{2} / \mathrm{CH}_{4}$ selectivity for the BIF-24 structure calculated by the IAST method $(273 \mathrm{~K})$ is $12: 1$. This high apparent selectivity for $\mathrm{CO}_{2}$ adsorption could be attributed to the possible interaction of $\mathrm{CO}_{2}$ with $\mathrm{B}-\mathrm{H}$ in the $\mathrm{HB}(\mathrm{mim})_{3}$ ligands in the boron imidazolate matrix. Thus, the presence of the favorable $\mathrm{B}-\mathrm{H}$ bonds in a high content contributes to the advantageous performance of BIF adsorbents in $\mathrm{CO}_{2}$ capture as compared to even ZIFs structures, which have been recognized as most prospective materials among the MOF family exploited in this field.

Furthermore, the BIF-24 material shows also remarkable adsorption capacities for light hydrocarbons $\left(\mathrm{CH}_{4}, \mathrm{C}_{2} \mathrm{H}_{4}, \mathrm{C}_{2} \mathrm{H}_{6}\right.$ and $\left.\mathrm{C}_{3} \mathrm{H}_{8}\right)$, e.g., in respect to $\mathrm{C}_{3} \mathrm{H}_{8}\left(88.5 \mathrm{~cm}^{3} \mathrm{~g}^{-1}, 174.2 \mathrm{mg} \mathrm{g}^{-1}\right)$, $\mathrm{C}_{2} \mathrm{H}_{6}\left(84.9 \mathrm{~cm}^{3} \mathrm{~g}^{-1}, 113.9 \mathrm{mg} \mathrm{g}^{-1}\right), \mathrm{C}_{2} \mathrm{H}_{4}\left(75.1 \mathrm{~cm}^{3} \mathrm{~g}^{-1}, 94.0 \mathrm{mg} \mathrm{g}^{-1}\right)$ and methane $\left(\mathrm{C}_{1}\right)\left(22.4 \mathrm{~cm}^{3} \mathrm{~g}^{-1}\right.$, $16.0 \mathrm{mg} \mathrm{g}^{-1}$ ) (Table 2). With an increase to room temperature, the adsorption capacities for $\mathrm{C}_{3} \mathrm{H}_{8}$ $\left(80.7 \mathrm{~cm}^{3} \mathrm{~g}^{-1}, 158.8 \mathrm{mg} \mathrm{g}^{-1}\right), \mathrm{C}_{2} \mathrm{H}_{6}\left(70.8 \mathrm{~cm}^{3} \mathrm{~g}^{-1}, 95.09 \mathrm{mg} \mathrm{g}^{-1}\right), \mathrm{C}_{2} \mathrm{H}_{4}\left(61.9 \mathrm{~cm}^{3} \mathrm{~g}^{-1}, 77.4 \mathrm{mg} \mathrm{g}^{-1}\right)$, and $\mathrm{CH}_{4}\left(14.6 \mathrm{~cm}^{3} \mathrm{~g}^{-1}, 10.4 \mathrm{mg} \mathrm{g}^{-1}\right)$ decrease following the trend involving the number of carbon atoms: $C_{3}>C_{2}>C_{1}$. Note that these adsorption results are comparable to the reported values for the flexible metal-organic frameworks UTSA-35a [82] and MFM-202a [83]. Therefore, the BIF-24 material can find a potential application in the hydrocarbon separation ( $273 \mathrm{~K}$ and RT).

Noteworthy, besides specific adsorbent-adsorbent interactions, commensurate adsorption plays also an important role in $\mathrm{CO}_{2}$ adsorption. Using $\mathrm{MOF}$ materials as adsorbents for carbon dioxide, their large channel spaces can be partitioned toward small $\mathrm{CO}_{2}$ molecules capture in order to realize commensurate adsorption.

An example of this helpful strategy is the BIF-41 material (Table 1) with pore space partition [42]. The partitioned channels in the BIF-41 porous structure show a pore size effect preference for $\mathrm{CO}_{2}$ and $\mathrm{H}_{2}$ over $\mathrm{N}_{2}$, as $\mathrm{CO}_{2}$ and $\mathrm{H}_{2}$ have smaller kinetic diameters than $\mathrm{N}_{2}$. The high selectivity towards $\mathrm{CO}_{2}$ and $\mathrm{H}_{2}$ can be attributed to small cages provided by pore space partition, which facilitates the interaction between small molecules and the channel walls. In particular, the $\mathrm{H}_{2}$ uptake values for the BIF-41 matrix are $106.4 \mathrm{~cm}^{3} \cdot \mathrm{g}^{-1}$ at $77 \mathrm{~K}$ and $83.4 \mathrm{~cm}^{3} \cdot \mathrm{g}^{-1}$ at $87 \mathrm{~K}$ (Table 2). However, these values are lower than that measured for the BIF-24 matrix with $c$ tn topology (Table 1, Table 2).

The $\mathrm{CO}_{2}$ uptake values measured for the BIF- 41 matrix are $77.0 \mathrm{~cm}^{3} \cdot \mathrm{g}^{-1}\left(3.44 \mathrm{mmol} \cdot \mathrm{g}^{-1}\right)$ at $273 \mathrm{~K}$ and $63.5 \mathrm{~cm}^{3} \cdot \mathrm{g}^{-1}\left(2.83 \mathrm{mmol} \cdot \mathrm{g}^{-1}\right)$ at $294 \mathrm{~K}$ (Table 2$)$, which are a bit lower than that measured for the 
BIF-24 matrix, but yet comparable to some highly porous ZIF adsorbents [6,33]. At a zero coverage, the enthalpy of $\mathrm{CO}_{2}$ adsorption for the BIF-41 material is $23.9 \mathrm{KJ} \cdot \mathrm{mol}^{-1}$. Therefore, the BIF-41 material may have a potential application as a selective adsorbent of $\mathrm{CO}_{2}$ and $\mathrm{H}_{2}$ over $\mathrm{N}_{2}$ [42].

\subsection{Reductive Catalysis}

A remarkable benefit of the presence of $\mathrm{HB}(\mathrm{mim})_{3}{ }^{-}$ligands comprising potentially active $\mathrm{B}-\mathrm{H}$ bonds is a possibility to reduce in situ deposited metal precursors into metal nanoparticles embedded into BIF porous hosts. In catalysis, in particular in reduction catalysis, in general, the nanohybrids based on BIF matrices and metal nanoparticles, mainly Au, Ag and Fe nanoparticles can be used. In more detail, the reductive catalysis applications for the BIF based materials will be described in the Section 4.

\subsection{Solid-State Photoluminescent and Mechanxochromic Properties of BIF Matrices}

Smart MOF materials with the ability to respond by changing their physico-chemical characteristics to various external stimuli, such as $\mathrm{pH}$, redox, light, magnetic field, temperature, ions and ultrasound, have attracted increased attention [84,85]. Switchable-responsive MOFs-based nanomaterials have been already explored for optical sensing [86] and heterogeneous catalysis [87].

However, there are a very limited number of metal-organic frameworks that are stimuli-responsive luminescent materials that tune their colors in response to an external stimulus. In this context, a practically important characteristics is a mechanochromism of some boron imidazolate frameworks that display distinct luminescence induced by simple mechanical grinding [43]. The corresponding stimuli-responsive mechanism involves a grinding process between chains or layers.

An example of mechanochromic luminescent material belonging to the BIFs family is the ladder-like chain BIF-34 structure (Table 1) [46]. The examinations of the mechanical-grinding-triggeredluminescence change of the BIF-34 structure shows that upon UV irradiation at $360 \mathrm{~nm}$ (RT), the emission maximum wavelength for the BIF-34 structure is $512 \mathrm{~nm}$. Note that the emission maximum wavelength for the $\mathrm{KBH}(\mathrm{dm}-\mathrm{bim})_{3}$ ligand is $452 \mathrm{~nm}$. Possibly, the emission could be assigned to the $\mathrm{Cu}-\mathrm{p}^{*} \mathrm{BH}(\mathrm{dm}-\mathrm{bim})_{3}$ metal-to-ligand charge transfer (MLCT).

The BIF-38 structure (Table 1) with 2-fold interpenetrating ths topology shows interesting luminescence mechanochromic properties [48]. Upon the irradiation with UV light at $330 \mathrm{~nm}$ (RT), the emission maximum wavelength for the BIF-38 matrix is $490 \mathrm{~nm}$, while the emission maximum wavelength for the $\mathrm{KBH}(\mathrm{im})_{3}$ ligand is $440 \mathrm{~nm}$. The emission of the BIF-38 matrix may occur due to the $\left[\mathrm{Cu} \rightarrow \pi^{*} \mathrm{HB}(\mathrm{im})_{3}{ }^{-}\right]$metal-to-ligand charge transfer (MLCT), which is characteristics for $\mathrm{Cu}(\mathrm{I})$ compounds. The emission spectrum indicates that the ground BIF-38 sample displays an obvious blue shift of about $23 \mathrm{~nm}$.

Structural examination shows that the crystal-to-amorphous phase conversion is caused by the grinding of the BIF-38 sample. Thus, the luminescent blue shift change in this material occurs due to the structural modification. It was pointed out that the $\mathrm{Cu} \cdots \mathrm{Cu}$ interactions in the BIF-38 structure played a vital role in the mechanochromism.

Two low-dimensional $\mathrm{Cu}(\mathrm{I})$ boron imidazolate frameworks, BIF-40 and BIF-6 (Table 1), with a $\pi-\pi$ stacked layer chain structure (Figure 6) display mechanochromism realized as mechanical-grinding-triggered-luminescence change [43]. In particular, the ground BIF-40 material displays a red shift about $20 \mathrm{~nm}$ in the emission spectrum $(\lambda \mathrm{em}=568 \mathrm{~nm}$ ), which indicates the behavior of the pressure-induced luminescence change for this boron imidazolate framework. Structural examinations of the ground BIF-40 sample showed that the crystal lattice is significantly disrupted. Thus, strong grinding causes a crystal-to-amorphous-phase conversion. Therefore, similar to the BIF-38 material with mechanocromic properties, the luminescent red shift change in BIF-40 is related to the structural modification. 


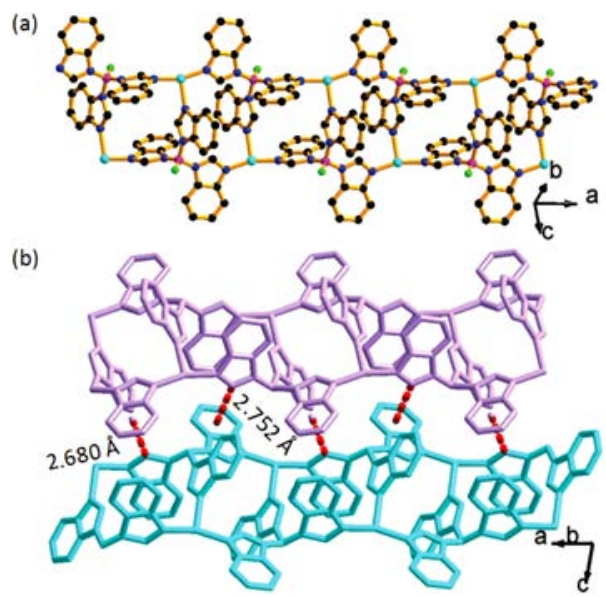

Figure 6. (a) View of the ladder-like chain in BIF-40; and (b) the packing view between chains in BIF-40, showing the $\mathrm{C}-\mathrm{H} \cdots \pi$ interactions (red dashedline) between the adjacent chains. Color codes: $\mathrm{Cu}$, pale blue; B, purple; C, black; N, blue; H, green. Partial H atoms are omitted for clarity. Reprinted with permission from [43].

Thus, it could be suggested that the reported results pave the way for the design and exploitation of boron imidazolate frameworks as mechanochromic materials with a potential applications as optic sensing.

Boron imidazolate framework BIF-77 with $\mathrm{Cd}^{2+}$ ions (Table 1) may be regarded as a multifunctional material with interesting solid-state photoluminescent properties and a promising porous host for noble metal nanoparticles (see the next section). Its photoluminescent activity arises from a combination of the mixed $\mathrm{HB}(\mathrm{bim})_{3}{ }^{-}$ligands and abdc linkers as organic building blocks in the structure [52]. It was shown that the emission of this boron imidazolate structure may be assigned to ligands and ligands-to-Cd charge transfer (LMCT), which is similar to those observed in some systems reported for d10 metal-organic frameworks with conjugated organic groups [88]. Upon irradiation with UV light with $340 \mathrm{~nm}$, the emission maximum wavelengths for the $\mathrm{KB}(\mathrm{im})_{4}$ ligand and the abdc ligand are 380 and $590 \mathrm{~nm}$, respectively. Additionally, the BIF-77 material exhibits a strong emission with the maximum wavelength at $430 \mathrm{~nm}$. Simultaneously, there is an absorption band-edge at $450 \mathrm{~nm}$ in the UV-vis diffuse reflectance spectrum of the BIF-77 sample. This visible-light absorption can be ascribed to the conjugated $\pi$ electron transition from the amino-containing abdc linkers as chromophores to the $\mathrm{Cd}$ centers. Thanks to this diverse solid-state photoluminescent behavior of the BIF-77 matrix, it may find a potential application in light emitting diodes (LEDs).

Another potential application field for BIF matrices with the solid-state photoluminescent properties is detection of aromatic molecules or sensing. An example is the zeolitic Cd(II)-boron imidazolate framework BIF-51 (Table 1) with ABW topology [50]. While constructing the BIF-51 material, the $[\mathrm{Cd}(\mathrm{ac})]^{+}$building units and $\mathrm{B}(\mathrm{im})_{4}{ }^{-}$ligands are assembled in the $3 \mathrm{D}$ open framework which features zeotype ABW topology. The free space in this matrix is $29.1 \%$ of its total volume. The BIF-51 material displays a remarkable luminescent emission and can be used for detecting nitrobenzene.

Further enrichment of the photoluminescent properties of the boron imidazolate frameworks is doping of these matrices with functional metal ions, first, belonging to the lanthanide group. Generally speaking, the encapsulation of $\mathrm{Ln}^{3+}$ (lanthanide) ions into the MOF matrices results in the formation of host-guest Ln@MOF structures with enhanced optical properties, such as intense luminescence and long lifetime [89].

An example of the modification of the photoluminescent properties of the BIF material with lanthanide ions is doping with mixed red-(Eu $\left.{ }^{3+}\right)$ and green- $\left(\mathrm{Tb}^{3+}\right)$ emitting ions in an appropriate ratio of the anionic blue emissive BIF-81 (Table 1) host matrix with $\mathrm{Cd}^{2+}$ coordination centers and aromatic carboxylate and tetradentate imidazolate ligands [53]. In this way, the Tb@BIF-81, Eu@BIF-81 and EuTb@BIF-81 host-guest materials were prepared. According to measurements with ICP techniques, 
the contents of $\mathrm{Eu}^{3+}$ and $\mathrm{Tb}^{3+}$ ions are 13.25 and $16.34 \mathrm{wt} . \%$. The PXRD study shows that the crystalline structure of the pristine BF- 81 framework remains intact after lanthanide ions loading.

Photoluminescent performance of the pristine BIF-81 structure realizes as a blue emission at $\sim 470 \mathrm{~nm}$ under excitation at $390 \mathrm{~nm}$, which is assigned to a ligand-to-metal charge transfer (LMCT: $\mathrm{O} / \mathrm{N}-\mathrm{Cd}$ ). In the host-guest Eu@BIF-81 materials, the unique peaks of $\mathrm{Eu}^{3+}$ appear at 578, 592, 613, 651 and $699 \mathrm{~nm}$, matching with the 5D0 $\rightarrow 7 \mathrm{FJ}(\mathrm{J}=0-4)$ transitions. As for Tb@BIF-81, the $\mathrm{Tb}^{3+}$ peaks are found at $488,543,582,588$ and $621 \mathrm{~nm}$, corresponding to the $5 \mathrm{D} 4 \rightarrow 7 \mathrm{FJ}(\mathrm{J}=6-3)$ transitions. For tuning the photoluminescent properties of the BIF-81 material, a series of host-guest $\mathrm{Eu}^{3+} / \mathrm{Tb}^{3+} @ \mathrm{BIF}-81$ samples with different molar ratios of $\mathrm{Eu}^{3+}$ and $\mathrm{Tb}^{3+}$ ions were studied. Using an optimal content of $\mathrm{Eu}^{3+} / \mathrm{Tb}^{3+}$ ions, $1 / 11$, in the BIF-81 porous host results in a white-light emission with excitation at $300 \mathrm{~nm}$ in the host-guest material.

Thus, blue emission of the pristine BIF structure can be tuned as a white-light emission in the $\mathrm{Eu}^{3+} / \mathrm{Tb}^{3+} @ \mathrm{BIF}-81$ host-guest material.

\subsection{Photocatalysis}

The particular photoluminescent properties of BIF matrices may contribute to their important photocatalytic applications. Noteworthy, hazardous dyes in water reservoirs can cause a number of negative impacts on the environment. One of the promising routes for the environment remediation and the purification of water resources is the photocatalytic degradation of the organic pollutants [90]. In particular, reduction methods and photocatalysis are considered to be the most promising approach for the purification of drinking water due to their ecology-friendly operation [91].

Currently, environment remediation using MOF materials as photocatalysts for the degradation of organic dyes draws an increased attention and becomes a hot research topic [92]. Along with MOF structures, BIF matrices can photocatalytically reduce the contaminant content in the environment and, most important, in drinking water. In this context, it is worth revealing what BIF structure characteristics are promising from photocatalytic point of view. For instance, the presence of the appropriate building blocks provide exploitation as photocatalysts for the boron imidazolate frameworks. For instance, some BIF matrices are photocatalytically active due to specific metal ions like $\mathrm{Co}^{2+}$ in their structures. An example is the BIF-58 matrix composed of boron imidazolate linkers and $\mathrm{Co}^{2+}$ ions as coordination sites (Table 1) [44]. These linkers are based on three pre-synthesized typical isolated boron imidazolate cages $\left(\mathrm{M}_{4} \mathrm{~L}_{4}, \mathrm{~L}=\right.$ imidazolate) [66]. Note that the BIF-58 matrix construction using boron imidazolate cages as building blocks is described in the Section 2 .

The photocatalytic active sites in the BIF-58 matrix are $\mathrm{Co}^{2+}$ ions due to their ability to absorb visible light. The BIF-58 matrix showed excellent photocatalytic efficiency for the degradation of methylene blue $(\mathrm{MB})$ in an aqueous solution under xenon arc lamp irradiation. The control tests show that ligand molecules $\left(\mathrm{BH}(\mathrm{bim})_{3}\right)$ are almost not active in the photodegradation. The MB degradation degree $\sim 50 \%$ occurs in $1 \mathrm{~h}$, while the complete degradation (99\%) time of MB is $5 \mathrm{~h}$. According to PXRD study, the BIF-58 structure remains almost intact after photocatalysis. The BIF- 58 photocatalyst is quite reusable and exhibits similar catalytic behavior in three consecutive photocatalytic cycles without any remarkable decrease in the degradation activity. According to photocatalysis mechanism proposed for the BIF-58 matrix, the reactive radical species such as $\mathrm{OH}^{-}$and $\mathrm{O}_{2}{ }^{-}$split the aromatic rings in the MB molecules.

Another example of the BIF-based photocatalyst is the Ag@BIF-77 nanohybrid in the form of the BIF-77 matrix with $\mathrm{Cd}^{2+}$ ions (Table 1) containing Ag nanoparticles [52]. In contrast to the BIF-58 matrix with photocatalytically active $\mathrm{Co}^{2+}$ ions, the BIF-77 material does not contain the photoactive coordination sites as metal ions. The photocatalytic performance of the Ag@BIF-77 nanohybrid is discussed in the next section relevant to BIF-based hybrid materials. 


\section{5. $\mathrm{CO}_{2}$ Photocatalytic Reduction}

To date, the increased fossil fuel consumption accompanied with an excessive emission of $\mathrm{CO}_{2}$ into the environment leads to a number of energetical and environmental concerns. Photocatalytic reduction of $\mathrm{CO}_{2}$ to energy-rich chemical fuels such as $\mathrm{CO}$ and $\mathrm{CH}_{4}$ is a promising process for $\mathrm{CO}_{2}$ conversion [93]. For this purpose, series of photocatalysts, including inorganic semiconductors, metal complexes and metal-modified zeolites, are explored. However, the development of photocatalysts for $\mathrm{CO}_{2}$ reduction featuring appropriate $\mathrm{CO}_{2}$ adsorption capacity and high density of active sites are highly demanded to address energy and environmental problems. In the modern literature, metal-organic frameworks including zeotype MOF structures are regarded as promising photocatalytic materials for $\mathrm{CO}_{2}$ reduction due to their flexible tunability in composition, structure and functional properties.

Along with other MOF structures, boron imidazolate frameworks have been recognized as functional photocatalytic materials with potential application in the $\mathrm{CO}_{2}$ reduction. In some cases, the performance of the BIF matrices as photocatalysts can be compared with that of ZIF matrices.

For instance, the BIF-101 framework (Table 1) based on trinuclear cobalt clusters as connecting nodes shows efficient photocatalytic performance in the $\mathrm{CO}_{2}$ reduction [55]. Its 3D pillar-layered structure composed of $2 \mathrm{D}$ layers constituted by $\mathrm{Co}_{3}\left(\mathrm{~m}_{2}-\mathrm{H}_{2} \mathrm{O}\right)_{2}(-\mathrm{COO})_{2}$ clusters and $\mathrm{BH}(\mathrm{mim})_{3}{ }^{-}$linkers in a combination with the nbdc ligand as a pillar. This BIF material has shown a preferable $\mathrm{CO}_{2}$ capture. Note that efficient adsorption and activation of $\mathrm{CO}_{2}$ molecules are key characteristics for the $\mathrm{CO}_{2}$ reduction. The highly porous BIF-101 matrix fits these requirements showing $\mathrm{CO}_{2}$ uptake values of $41.9 \mathrm{~cm}^{3} \mathrm{~g}^{-1}(273 \mathrm{~K})$ and $25.8 \mathrm{~cm}^{3} \mathrm{~g}^{-1}(298 \mathrm{~K})$ under $1 \mathrm{~atm}$ (Table 2). This photocatalyst demonstrates an efficient $\mathrm{CO}_{2}$ photochemical reduction using $\left[\mathrm{Ru}(\mathrm{bipy})_{3}\right] \mathrm{Cl}_{2}$ as a photosensitizer and triethanolamine as a sacrificial reagent. It was suggested that the BIF-101 matrix can accept excited electrons from the photosensitizer and provide catalytically active sites for $\mathrm{CO}_{2}$ reduction to facilitate the photoreduction. Using the BIF-101 material, $583 \mathrm{mmol}$ of $\mathrm{CO}$ and $110 \mathrm{mmol}$ of $\mathrm{H}_{2}$ with a selectivity of $84.1 \%$ for $\mathrm{CO}$ over $\mathrm{H}_{2}$ were obtained under visible-light irradiation $(10 \mathrm{~h})$. This is about an order more effective than in the case of a Co-ZIF-9 photocatalyst [94,95].

Furthermore, using BIF-101 photocatalyst, the production evolution rate is higher than that of reported composite BIF-20@g- $\mathrm{C}_{3} \mathrm{~N}_{4}$ sheet $(20$ wt.\% carbonitride; see next section) $-69.4 \mathrm{mmol} \mathrm{g}^{-1} \mathrm{~h}^{-1}$-and some MOF-based materials under visible light irradiation. Note that syngas with a $\mathrm{CO} / \mathrm{H}_{2}$ ratio between 0.5 and 1 is required for producing liquid fuels according to Fischer-Tropsch synthesis in modern industrial processes [55,96].

Moreover, the BIF-101 matrix shows an excellent chemical stability in aqueous solutions over a broad $\mathrm{pH}$ range from 2 to 12 preserving its structural integrity, which paves a bright avenue for its practically relevant applications.

An interesting attempt to develop the BIF-based photocatalytic materials through self-assembly of the pre-synthesized boron imidazolate cages is the preparation of the BIF-33 structure (Table 1 and Section 2) using the BIF-29 cage with six isolated coordinatively unsaturated $\mathrm{Cu}$ sites $\left(\left[\mathrm{Cu}_{6}\left[\mathrm{BH}(\mathrm{im})_{3}\right]_{8}\right]-\left(\mathrm{H}_{2} \mathrm{O}\right)_{6} \cdot 3\left(\mathrm{NO}_{3}\right) \cdot 4 \mathrm{H}_{2} \mathrm{O}\right)$ [45]. The BIF-33 material was obtained via cross-linking of this pre-synthesized $\mathrm{Cu}_{6} \mathrm{~B}_{8}$ cage with iodine-coordinated $\mathrm{Cu}$ sites. The BIF-29 cage itself shows a catalytic efficiency for the photocatalytic reduction of $\mathrm{CO}_{2}$ to $\mathrm{CO}$ due to $\mathrm{Cu}^{2+}$ open sites (Figure 7). In this reaction, $\left[\mathrm{Ru}(\mathrm{bpy})_{3}\right] \mathrm{Cl}_{2}$ was used as the photosensitizer, and triethanolamine (TEOA) as the sacrificial reagent. The photocatalytic activity is imparted to the BIF-33 material by using the BIF-29 cage as a building block. However, the evolution rate of $\mathrm{CO}\left(3334 \mathrm{mmol} \mathrm{g}^{-1} \mathrm{~h}^{-1}\right.$ for BIF-29 is 3 times of the value ( $1185.4 \mathrm{mmol} \mathrm{g}^{-1} \mathrm{~h}^{-1}$ ) for BIF-33, and the selectivity of $82.6 \%$ for the BIF-29 cage is also higher than that of $76 \%$ for the 3D BIF-33 material. 


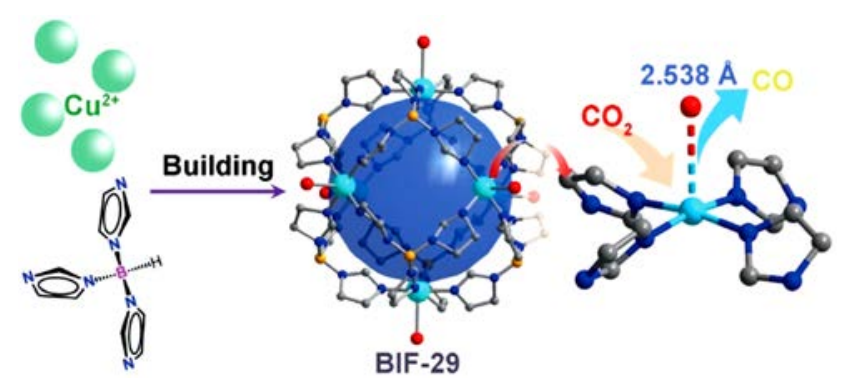

Figure 7. Schematic illustration of the synthesis of BIF-29 (right) and the $\mathrm{CO}_{2}$ adsorption and activation over unsaturated coordinated $\mathrm{Cu}$ site (left). Broken line indicates weak bond to water oxygen atom. $\mathrm{Cu}$, cyan; $\mathrm{B}$, yellow; $\mathrm{O}$, red; $\mathrm{C}$, gray; $\mathrm{N}$, blue. $\mathrm{H}$ atoms are omitted for clarity. Reprinted with permission from [45].

\subsection{Electrocatalysis}

Electrochemical water splitting is a promising method for storing light/electrical energy in the form of $\mathrm{H}_{2}$ fuel; however, it is limited by the sluggish anodic oxygen evolution reaction (OER). To achieve sufficient $\mathrm{H}_{2}$ production, efficient OER catalysts with a large surface area, dense active sites and appropriate stability are highly demanded [97]. Currently, a large variety of different kind of catalysts based on non-noble metals, i.e., $\mathrm{Mn}, \mathrm{Fe}, \mathrm{Co}$ and $\mathrm{Ni}$, including metal oxides [98], hydroxides [99] and perovskites [100], are usually utilized in OER.

Very recently, BIF-matrices and BIFs-derived materials have been recognized as promising heterogeneous catalysts for OER as well as for electrochemical reduction of $\mathrm{CO}_{2}$ to $\mathrm{CO}\left(\mathrm{CO}_{2} \mathrm{RR}\right)$. An essential BIF characteristic allowing one to use them in electrochemistry is their stability in aqueous solutions. Note that many MOF matrices show a poor stability in water media. A degradation of the crystalline structure and porosity loss in aqueous electrolytes (strong acid or alkali) limits the applications of the functional MOF materials in energy-related electrocatalysis. The stability of MOF materials in water is attributed to their inherent frameworks, namely coordinated metal ions, hydrophobicity of organic ligands and metal-ligand and coordination geometry [101]. Consequently, few MOF matrices have been reported, which are used as electrocatalysts in acid and alkaline solutions $[102,103]$. Therefore, designing new MOF materials with intrinsic stability is important for their applications in electrocatalysis.

In terms of stability in aqueous solutions, BIF materials have some advantages with respect to some known MOF materials. Uniformly distributed three- or four-connected boron components as boron imidazolate linkers contribute to the BIF framework rigidity.

An example of the alkaline-stable anionic boron imidazolate framework, BIF-89 (Table 1) with potential application in electrocatalysis was reported in [54]. Its structure remains intact in common solvents such as water and DMF. Note that the BIF-89 matrix showed a poor activity in OER, because the coordinated $\mathrm{Cd}$ atoms in the framework are electrocatalytically inert. However, it is well known that doping with $\mathrm{Co}^{2+}$ or $\mathrm{Fe}^{3+}$-ions may enhance the performance of the electrocatalytic materials serving as highly active sites and reducing the overpotential for this process $[97,104]$. To optimize the electrocatalytic performance, $\mathrm{Fe}^{3+}$-ions were introduced in the BIF- 89 matrix resulting in the Fe@BIF-89 host-guest material. The advantages of the mixed linkers, e.g., boron imidazolate and phenylene tetracarboxylate have been demonstrated, because the uncoordinated carboxylic groups in btec linkers of the BIF-89 framework can stabilize introduced $\mathrm{Fe}^{3+}$ ions in this porous host. The Fe@BIF-89 electrocatalyst exhibits an efficiency in OER in strongly alkaline media. Therefore, this BIF- 89 structure can be regarded as a true multifunctional material, because it exhibits also a unique mechanochromic behavior with a maximum emission blue shift of about $23 \mathrm{~nm}$ in the blue emitting range. The luminescence mechanochromism of the BIF-89 matrix expands its potential application fields including electrocatalytic applications. 
The efficiency of the bimetallic systems in the form of Co-based BIF matrices with incorporated $\mathrm{Fe}^{3+}$ ions was also demonstrated by modifying the Co-based BIF-91 matrix (Table 1) with mixed boron imidazolate and phenylene carboxylate linkers similarly to the BIF-89 matrix [40]. Note that unlike the BIF-89 framework, the BIF-91 structure has electrocatalytically active sites, i.e., $\mathrm{Co}^{2+}$ ions as coordination centers in the framework. In this matrix, the carboxylate groups divide channel spaces into multiple domains in which each single channel is filled with ndc ligands. Thus, the presence of ndc linkers in the BIF-91 channels decreases its pore size and therefore increases the density of the coordination bonds. This specific pore structure contributes to the BIF-91 framework integrity in strong alkaline solutions. One more stabilizing effect of the ndc ligands is provided by their action as a rigid auxiliary linker due to $\mathrm{C}-\mathrm{H} \cdots \pi$ interaction. As a result, the structural stability of the BIF-91 framework in harsh alkaline conditions surpasses the chemical stability of other zeolite-like metal-organic frameworks, e. g., BIF-22 and ZIF-67 [105] matrices.

In the formation of the Fe@BIF-91 host-guest structure, the $\pi$-conjugated effect of mixed organic linkers with the rich (hetero)aromatic moieties in the BIF-91 matrix stabilizes dopant $\mathrm{Fe}^{3+}$ ions at the atomic scale. The Fe@BIF-91 host-guest material shows synergistically enhanced OER activity in strong alkaline media $(\mathrm{pH} \approx 14)$. Due to the synergistic effect between guest $\mathrm{Fe}^{3+}$ ions and $\mathrm{Co}^{2+}$ ions as inorganic nodes in the BIF-91 framework, the Fe@BIF-91 material shows an enhanced electrochemical activity when compared with Fe@BIF-89 host-guest structure containing only doping $\mathrm{Fe}^{3+}$ ions. Furthermore, the BIF-91 material shows an enhanced catalytic performance as compared to other common metal catalysts for water oxidation under strong alkaline conditions.

\section{BIF Nanohybrids with Metal Nanoparticles}

A high porosity and rich functionality of MOF matrices makes them advanced platform materials for a large varieties of hybrid materials with potential applications in many important fields. Among them a particular place takes the fabrication of the functional nanohybrids in the form of MOF matrices containing deposited or embedded metal nanoparticles that can be used in heterogeneous catalysis [106], molecular recognition, sensing and optics [107]. For at least a decade, extensive research efforts have been focused on the fabrication of metal nanoparticles (M-NP) in MOF matrices for creating a bunch of practically sound properties that are hardly achieved by the individual components of M-NP@MOF nanohybrids [108].

The utilization of MOF materials as supports for M-NP has several advantages over other porous materials, such as activated carbons, silicas, zeolites and metal oxides. Actually, fully open porous structures, tunable structural characteristics and pore geometry, presence of organic linkers with functional groups along with a confinement effect can stabilize M-NP in MOF matrices. It can not only significantly improve the catalytic performance and stability of the M-NP, but also engender the unique electronic phenomena and space-confined effects of MOF porous hosts and impart a number of additional functional characteristics that are lacking in pristine MOF matrices [109]. Therefore, this area has become one of the "hot topics" [56].

In particular, loading of M-NP into porous MOF hosts is a prospective way for the advanced catalyst preparation [110]. In this context, zeotype MOF matrices, including zeolitic imidazolate frameworks are promising as supports for metal nanoparticles with potential application in heterogeneous catalysis [111].

Usually, most often reported M-NP@MOFs were synthesized by: (i) a ship-in-a-bottle strategy in which the MOF is pre-synthesized, and M-NP are loaded via liquid phase infiltration and solid grinding into the pores; or (ii) a bottle-around a-ship approach where the M-NP and metal clusters are first synthesized and after modification the M-NP are added to the reactor with the ligand. However, the morphology and size of the M-NP are relatively difficult to control by these methods, and surfactants have to be added to prevent the agglomeration before coating. Therefore, it is particularly important to in-situ synthesize nanoparticles with a highly uniform dispersion and size by using the space-confined effect of the MOF host matrices. 
There are a few general synthesis methods to embed M-NP in a porous solid, which involve the impregnation of a metal precursor, followed by its reduction to metal( $(0)$ atoms, which further aggregate into M-NP within the solid matrix. Depending on the metal and support nature, several reducing techniques are usually exploited, such as reduction in a hydrogen flow [112] in a combination with inert gases such as argon [113], thermal decomposition or the use of external reducing agents such as $\mathrm{NaBH}_{4}$ [114]. In some cases, a supercritical $\mathrm{CO}_{2}{ }^{-}$methanolic solution has been used to load the precursor compound within a MOF followed by a heating process [115].

Note that the morphology and size of the M-NP are relatively difficult to control by the listed preparation methods. In addition, external reducing agents can also enable the possible reduction of noble metal precursors on external surfaces of the MOF host. These obstacles decrease the pore confinement effects, which maintain a high dispersion of M-NP, and therefore the size-sensitive selectivity of the resulting catalysts. Therefore, it is particularly important to develop the efficient approaches for the in-situ preparation of the metal nanoparticles with a high and homogeneous dispersion, which allows one to realize the stabilizing effect of the highly porous MOF matrices.

Some MOF matrices display promising capability to reduce in situ introduced metal precursors into metal nanoparticles due to their intrinsic functionality. For instance, several redox-active - $\mathrm{COOH}$ and $-\mathrm{OH}$, uncoordinated functional groups containing $\mathrm{ntb}_{3}-\left(\mathrm{ntb}=4,4^{\prime}, 4^{\prime \prime}\right.$-nitrilotrisbenzoate), amine groups and $\mathrm{Ni}(\mathrm{II})$ macrocyclic species can reduce metal precursors to M NPs without external reducing agents [116]. In particular, Zn-MOF-74 framework provides the ultrafast and one-step formation of the $\mathrm{Fe}_{2} \mathrm{O}_{3} @$ MOF hybrid due to dihydroxyterphthalate linkers [117]. Notably, the M-NP@MOF nanohybrids synthesized by this in-situ reduction strategy may display excellent catalytic activity and selectivity, due to a high dispersion and homogeneous distribution of M-NP in the MOF porous host.

As to M-NP@BIFs hybrids, along with MOF materials, BIF matrices are studied intensively as supports or porous hosts for the metal nanoparticles deposition [56]. The M-NP@BIFs nanohybrids formed in this way can be used in catalysis or in biomedical applications, for instance, as antibacterial drugs. In this context, it is important to outline the BIF distinct properties relevant to the M-NP in situ fabrication in the boron imidazolate matrices. Several specific advantages of the usage of BIF supports are known for the M-NPs@BIF nanohybrids. Conversely, there are intrinsic advantages of the highly porous MOF matrices with a high crystallinity. Indeed, BIF structures are a member of the MOF family.

As it is mentioned in the previous sections, the decisive aspect providing an advanced usage of the BIF matrices with tripodal imidazolate linkers as porous hosts for metal nanoparticles is the presence of B-H bonds in the $\mathrm{HBim}_{3}{ }^{-}$moiety. A high density of B-H bonds in BIF pores allows one to reduce metal precursors incorporated in these hybrid matrices into nanoparticles without any additional reducing agents. The advantages of this method are obvious. Such framework B-H functionality along with pore confinement effects and size control of the boron imidazolate frameworks provides a base for advantageous M-NP@BIF nanohybrid preparation. For instance, the fabrication of Ag nanoparticles with a high dispersion under mild conditions is a challenging task [56].

An example of the advantage of $\mathrm{BIF}$ matrices with $\mathrm{BH}(\mathrm{mim})_{3}$ ligands able to produce M-NP due to B-H bonds with reduction function is the preparation of a M-NP@BIF nanohybrid based on BIF-20 [41]. For these $\mathrm{HB}(\mathrm{mim})_{3}{ }^{-}$based BIFs, there exists a high density of $\mathrm{B}-\mathrm{H}$ bonds on the $\mathrm{HB}(\mathrm{mim})_{3}$ ligands in the framework. The presence of potentially active B-H bonds in the coordinated $\mathrm{HB}(\mathrm{mim})_{3}$ ligands may act as the reducing agent and contribute to the direct formation of M-NPs in BIF-20 crystals [77]. B-H groups decorating the internal pore surface in the porous BIF-20 matrix produce effectively small $\mathrm{Ag}$ or Au nanoparticles within its confined pore space without any additional (photo)reducing agents (Figure 8). 
(a)

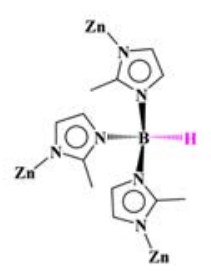

(c)

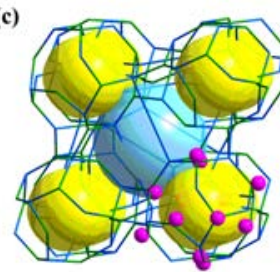

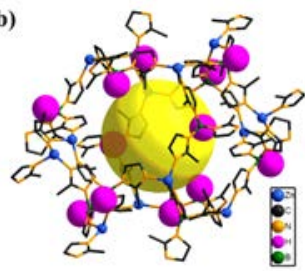

(d)

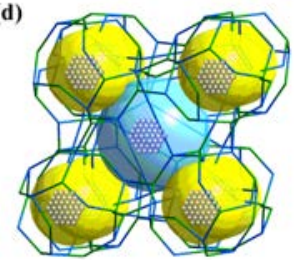

Figure 8. (a) The coordination mode of $\mathrm{BH}(\mathrm{mim})_{3}{ }^{-}$ligand; (b) the rich $\mathrm{B}-\mathrm{H}$ bonds. ( $\mathrm{H}$ atoms bonded to B centers are highlighted as purple balls) in the SOD cage of BIF-20; (c) the interrupted LTA-type framework of BIF-20, showing large cavities represented by the yellow and sky-blue balls; and (d) a schematic representation of the loading of NPs into the cavities of BIF-20. Reprinted with permission from [77].

It was found that this way provides a number of different oxidation states of Au. According to physico-chemical characterization, $\mathrm{Au}(0)$ and $\mathrm{Au}^{3+}$ species coexist in the Au@BIF-20 solid. The structural examination indicates that the host BIF-20 framework is retained after the loading of Ag-NP. Note that the boron imidazolate framework BIF-25 $\left(\mathrm{Co}_{2}\left[\mathrm{~B}(\mathrm{im})_{4}\right]_{4}, \mathrm{im}=\right.$ imidazolate $)$ without B-H bonds in imidazolate linkers was employed to repeat the in situ formation of the metal nanoparticles similar to the BIF-20 material. However, no M-NP can be produced in the BIF-25 matrix with no B-H bonds in the linker. The authors tested the possibility for the $\mathrm{HB}(\mathrm{mim})_{3}$ ligand itself to reduce $\mathrm{Ag}^{+}$or $\mathrm{Au}^{3+}$ species to metal (0). In these tests, two oxidation products in the reaction solution, $\mathrm{B}(\mathrm{mim})_{3}\left(\mathrm{OCH}_{3}\right)_{2}$ and $\mathrm{B}(\mathrm{mim})_{3}(\mathrm{OH})_{2}$ were also formed. Thus, the $\mathrm{B}-\mathrm{H}$ bonds in the BIF-20 matrix play a dominant role in producing $\mathrm{M}-\mathrm{NP}$.

Compared to the pristine BIF-20 material, the resulting Ag@BIF-20 and Au@BIF-20 nanohybrids show high catalytic activities for the reduction of 4-nitrophenol (a common reagent in the production of drugs, dyes, fungicides and pesticides) into 4-aminophenol. This reaction is of practical importance in the ecology as a way for the removal of the toxic phenol derivatives from the environment including aquatic media. The catalytic reduction of 4-nitrophenol over BIF-20-based nanocatalysts results in 4-aminophenol without byproducts formation. This reaction is considered as pseudo-first-order regarding to the reactant. The Ag@BIF-20 catalyst displays a higher activity than the Au@BIF-20 nanohybrid. Notably, the catalytic efficiencies of the BIF-20 based nanohybrids is superior to a number of other Au- and Ag-based heterogeneous systems under ambient conditions [118].

The Ag@BIF-20 and Au@BIF-20 nanocatalysts obtained in this way show a good reusability and can be exploited without any activity loss during at least four cycles. Noteworthy, according to TEM measurements, a high dispersion of Ag and Au NPs is preserved after the catalytic reaction.

It is important that this strategy is equally efficient in the preparation of sophisticated core-shell nanostructures. For instance, the Au@BIF-20 crystal contains Au-NP "core" surrounded by a clear NP-free shell which illustrates that the redox reaction to produce Au NPs may slowly progress from the core towards the shell [15].

The Ag@BIF-34 hybrid nanocatalyst was synthesized by directly producing Ag nanoparticles with rich $\mathrm{B}-\mathrm{H}$ bonds in the matrix of the redox-active $\mathrm{Cu}(\mathrm{I})$ boron imidazolate framework BIF-34 (Table 1 and Section 2) [46]. The TEM study of the Ag@BIF-34 material indicates the formation of very small, around $2.0 \mathrm{~nm}, \mathrm{Ag}$ NPs in the BIF-34 matrix. The Ag@BIF-34 nanohybrid shows a much higher activity for the reduction of 4-nitrophenol as compared to the pristine BIF-34 matrix. 
An important strategy is a preparation of M-NP@BIF nanohybrids starting from BIF matrices with mixed linkers by the action of both reducing B-H groups in the tripodal linkers of the BIF matrices and other functional groups, such as hydroxyl and amino groups in the second-type organic linkers. An example is the preparation of the Ag@BIF hybrid catalyst by the same in situ method starting from zeolitic Cd(II)-boron imidazolate framework BIF-51 with mixed linkers, namely tridentate boron imidazolate and acetate [50]. In this case, Ag-NP were produced in the BIF-51 porous host using tridentate boron imidazolate containing $\mathrm{B}-\mathrm{H}$ bonds as a kind of moderate reducing agent. The TEM tests of the resulting nanohybrid indicated the formation of the highly dispersed Ag-NP in the BIF-51 matrix.

The catalytic properties of the Ag@BIF-51 nanohybrid in the same model reaction of the reduction of 4-nitrophenol were probed. According to these examinations, the BIF-51-based nanocatalyst shows an enhanced catalytic performance in the reduction of 4-NP. Interestingly, the catalytic efficiencies of the Ag@BIF-51 and Ag@BIF-20 nanocatalysts are comparable. Notably, the crystalline BIF-51 structure in the Ag@BIF-51 nanohybrid retains not only after Ag-NP loading, but also after three catalytic cycles of 4-NP reduction.

The considered strategy involving the synthesis in-situ of the M-NP@BIF nanohybrids was demonstrated also for the zinc-based boron imidazolate framework with mixed linkers, namely 2-methylimidazolate and obb, Zn-BIF (Table 1 and Figure 9). It should be noted that these hybrid nanomaterials can be considered as multifunctional and multipurpose materials with potential applications in catalytic removal of toxic substituted nitrophenols (by reduction), photodegradation of organic dyes and the inactivation of bacteria in water [56].

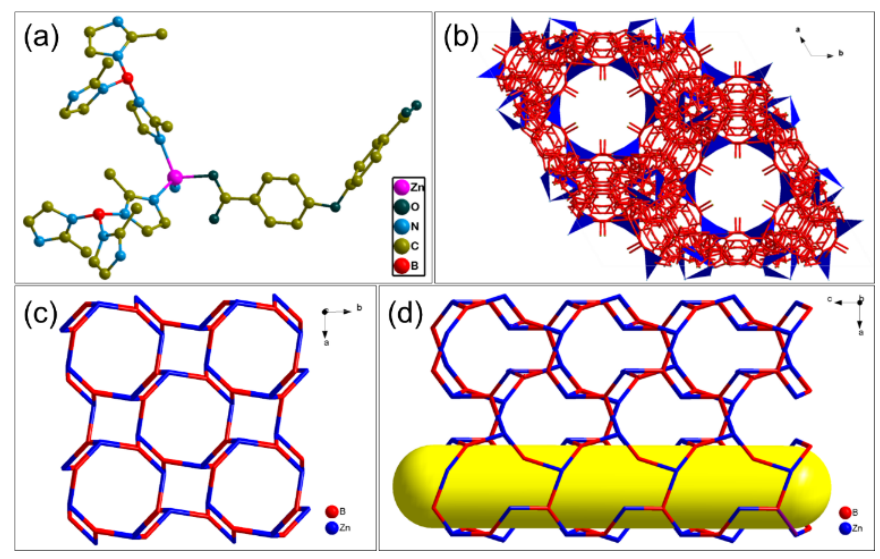

Figure 9. (a) The coordination environment of Zn-BIF; (b) the 3D framework with 1D channels; and (c), (d) the topological structure of Zn-BIFs. Reprinted with permission from [56].

M-NP@Zn-BIF (M-NP = Ag or Cu nanoparticles) hybrid catalysts were prepared at room temperature due to the reducing ability of $\mathrm{B}-\mathrm{H}$ bonds distributed in the $\mathrm{Zn}$-BIF matrix without additional agents. Using these nanohybrids, the catalytic reduction of a number of substituted nitrophenols was studied. For instance, Ag-NP@Zn-BIF nanomaterial exhibits excellent catalytic activity in reduction of 4-NP into 4-aminophenol in 6 min with a conversion as high as 99.9\%. The M-NP@Zn-BIF nanohybrids show also catalytic activity in the reduction of 2-nitrophenol, 3-nitrophenol, 2,4-dinitrophenol and 2,4,6-trinitrophenol.

Furthermore, M-NP@Zn-BIF nanohybrids were also studied in the ecologically relevant photodegradation of Rhodamine B. They demonstrated a high photocatalytic activity for degradation of this organic dye. Using the dye concentration as high as $1000 \mu \mathrm{g} / \mathrm{mL}$, the photocatalytic efficiency of Ag-NP@Zn-BIF and Cu-NP@Zn-BIF nanomaterials increased by 31.62 and 18.13 times compared with Zn-BIF, respectively.

The antibacterial activity of the M-NP@Zn-BIF nanohybrids was also evaluated using a growth curve method, plate counting method, and Acridine orange-Propidium iodide fluorescence double 
staining. In addition, Ag-NP@Zn-BIF (50 $\mu \mathrm{g} / \mathrm{mL})$ showed highly synergistic antibacterial activity against both Escherichia coli (E. coli) and Staphylococcus aureus (S. aureus) with a bactericidal rate of approximately $99.9 \%$. An antibacterial mechanism was proposed for the generation of intracellular reactive oxygen species, namely superoxide radicals $\left(\mathrm{O}^{2-}\right)$ and hydroxyl radicals $(\mathrm{OH})$.

Noble metal nanoparticles can be formed in the BIF matrices due to cooperative action of the B-H bonds from tridentate boron imidazolate ligands and additional linkers containing functional groups with a potential reducing capability, for instance $-\mathrm{NH}_{2}$ groups introduced in the 2-benzene-1,4-dicarboxylate ligand.

The Ag-NP@BIF-77 nanohybrid with potential applications in photocatalysis was produced by an in situ approach involving the formation of the Ag nanoparticles under RT conditions in the BIF-77 matrix due a cooperative action of $\mathrm{BH}(\text { bim })_{3}{ }^{-}$linkers containing $\mathrm{BH}$ bonds and functionalized $-\mathrm{NH}_{2}$ groups in the abdc linkers [52]. The TEM results indicate the formation of Ag-NP in the BIF-77 matrix. Further, the physico-chemical characterization reveals a coexistence of $\operatorname{Ag}(0)$ and $\mathrm{Cd}^{2+}$ species in the nanohybrid. The photocatalytic activity of the Ag@BIF-77 nanohybrid was investigated to degrade methylene blue (MB). The Ag@BIF-77 nanomaterial showed excellent photocatalytic performance for the degradation of $\mathrm{MB}$ in aqueous solutions. Its photocatalytic activity was gradually enhanced with time. After $60 \mathrm{~min}$, the degradation ratio of MB reaches $99 \%$. Note that the photocatalytic process over the Ag@BIF-77 nanocatalyst proceeds much faster than using the BIF-58 material in degradation of MB due to doping of Ag-NP. It is important to note that the Ag@BIF-77 nanohybrid shows a good reusability in this photocatalytic reaction.

These results confirm the importance of the usage of second-type organic linkers having functional groups with reducing capability for the construction of the nanohybrids based on the functional BIF host matrices. An important strategy involves a design and synthesis of BIF structures using tetradentate boron imidazolate ligands and functionalized auxiliary polycarboxylate linkers that can reduce metal precursors into metal nanoparticles.

An interesting example of this approach is the synthesis of the Ag-NP@BIF- 80 nanohybrid by Liu et al. [53]. Ag nanoparticles were produced in the BIF-80 matrix (Table 1) due to uncoordinated hydroxyl groups $(-\mathrm{OH})$ counterions with reduction activity in dht linkers without extra reducing agents. According to the structural examinations, the BIF- 80 framework remains intact after the loading of Ag-NP (as high as 3.163 wt.\%). Physicochemical results reveal the coexistences of $\mathrm{Ag}(0)$ and $\mathrm{Cd}^{2+}$ species in the Ag-NP@BIF-80 nanohybrid. This nanomaterial shows enhanced photoluminescence properties as compared to the pristine BIF- 80 matrix under RT conditions. In particular, the emission spectrum showed a blue shift about $36 \mathrm{~nm}$ in the Ag-NP@BIF-80 nanohybrid, which may be assigned to the surface plasmons in spherical Ag nanoparticles.

The bimetallic nanohybrids based on BIF supports are of particular interest due to their advanced performance in a number of practically important application fields, including catalysis [119]. This strategy toward the construction of nanohybrids M-NP@BIFs is also demonstrated by other examples, such as bimetallic AuAg-NP@BIF-38 [48].

The BIF-38 matrix with mechanochromic properties (see the previous section) displays redox-activity due to $\mathrm{BH}$ groups in the tripodal $\mathrm{HB}(\mathrm{im})_{3}$ ligands selected for directly reducing bimetallic Au-Ag nanoparticles introduced in this matrix. The AuAg-NP@BIF-38 nanomaterial was synthesized according to a two-step process. The TEM study indicates the formation of small $\mathrm{Au}-\mathrm{Ag}$ bimetallic nanoparticles with a size of $\sim 20 \mathrm{~nm}$ in the BIF-38 matrix. The AuAg-NP@BIF-38 nanohybrid shows a high catalytic activity in the reduction of 4-NP. Notably, a high dispersion of $\mathrm{Au}-\mathrm{Ag}$ nanoparticles retains after three catalytic cycles over the AuAg-NP@BIF-38 nanomaterial.

One more example of in situ loading of bimetallic Au-Pd nanoparticles in the BIF matrices is related to the preparation of a AuPd-NP@BIF-40 nanohybrid using $\mathrm{Cu}(\mathrm{I})$ boron imidazolate framework BIF-40 as a porous host (Table 1) [43]. The BIF-40 matrix produced directly Au-Pd bimetallic nanoparticles embedded in it due to the rich $\mathrm{B}-\mathrm{H}$ bonds homogeneously distributed in its structure. The AuPd-NP@BIF-40 nanomaterial shows a high catalytic efficiency in the model 4-NP reduction 
that is common for probing activity of the M-NP@BIF nanohybrids. Notably, the activity of the tested bimetallic system remains unchanged in three catalytic cycles, which confirms a good catalytic reusability of the AuPd-NP@BIF-40 nanohybrid. At the same time, the size of Au-Pd nanoparticles do not change after recycling tests, again confirming a possibility of multiple usage of this catalytic system.

The previous literature examples of the preparation of M-NP nanocatalysts involve a direct incorporation of metal nanoparticles with different sizes into BIF matrices using the rich active $\mathrm{B}-\mathrm{H}$ bonds in the tridentate boron imidazolate ligands as reducing agents.

It is interesting to outline the potential of BIF materials with four-connected boron imidazolate linkers as the carriers for metal nanoparticles with controllable dispersion. An example of this strategy is the utilization of the BIF-39(Cd) matrix based on tetrahedral $\mathrm{M}^{2+}$ as metal nodes and two kinds of organic building blocks, $\mathrm{B}(\mathrm{im})_{4}{ }^{-}$and $\mathrm{C}_{2} \mathrm{O}_{4}{ }^{2-}$ (Table 1) for embedding bimetallic $\mathrm{Au}-\mathrm{Pd}-\mathrm{NP}$ with an exceptionally small average size-around $2.12 \mathrm{~nm}$ [49]. Au-Pd NP were loaded in the BIF-39(Cd) porous host using $\mathrm{KBH}(\mathrm{dm}-\mathrm{bim})_{3}$ as a moderate reducing agent. The authors pointed out that the resulting $\mathrm{Au}-\mathrm{Pd}$ nanoparticles also have a smaller size and more uniform distribution, compared with other reported M-NP@BIF nanohybrids based on boron imidazolate frameworks with tripodal linkers containing B-H functional bonds possessing moderate reductive ability. The smaller size of the Au-Pd bimetallic nanoparticles embedded in the BIF-39(Cd) matrix should be explained by the presence of the $\mathrm{B}-\mathrm{H}$ bond in the $\mathrm{KBH}(\mathrm{dm}-\mathrm{bim})_{3}$ reducing agent as well as the pore confinement effect of the $1 \mathrm{D}$ channels in this boron imidazolate framework, stabilizing bimetallic $\mathrm{Au}-\mathrm{Pd}$ nanoparticles on the pore surface. The high dispersion of the active phase in the Au-Pd-NP@BIF-39(Cd) nanocatalyst results in its efficient performance in 4-NP reduction and good catalytic stability.

Note that the preparation of trimetallic NP-containing catalysts along with bimetallic catalytic systems is still a challenging task. For this purpose, the rather sophisticated procedures are commonly required [120]. A rare example of the synthesis of such trimetallic nanocatalysts is direct embedding of $\mathrm{Au}-\mathrm{Ag}-\mathrm{Pd}$ nanoparticles in the BIF-36 porous host (Table 1 ) by a two-step process involving simultaneous introducing Au and Pd nanoparticles followed by Ag-NP deposition (RT conditions) [47]. The formation of M-MPs of three different kinds was achieved due to the presence of B-H bonds in the $\mathrm{BH}(\mathrm{dm}-\mathrm{bim})^{3-}$ linkers, which impart redox activity in the BIF-36 matrix serving as the reducing agent.

The trimetallic Au-Ag-Pd@BIF-36 nanocatalyst shows a good activity in the reduction of 4-nitrophenol. Its reusability was studied in three catalytic cycles, in which it demonstrated similar catalytic activity without remarkable loss of the conversion values for the same reaction time.

Thus, the distinct potential of the BIF matrices for the preparation of the nanocatalysts with different M-NP structures and compositions, sometimes rather sophisticated is clearly revealed from the contemporary literature.

\section{BIF-Based Composites with Graphitic Material}

Carbon-based materials have found extensive applications in many fields including environment remediation in the gas and liquid phase as well as energy storage. These supports possess a number of favorable characteristics, ranging from high mechanical and elastic strength, excellent chemical and thermal robustness and distinguished electronic and optical properties to low weight and low toxicity. Therefore, integration of MOF matrices as a kind of the modern hybrid structures with carbon-based materials is the way to impart a number of novel functionalities such as improved conductivity and stabilities, template effects, etc. To the formed functional composites for an enhancement of their properties towards specific tasks [121]. These novel functionalities are arising from the synergistic effects (mainly chemical composition, porous system or structure changes) of the two components, namely MOF matrices and carbon matrices. An example is an increase of the stability of MOF matrices in water. Since most carbon-based materials possess excellent stabilities towards water/vapor, high temperature, mechanical strength, etc., MOF/carbon composites may possess these characteristics. Due to these cooperative effects, functional composites of MOF materials with carbon matrices are promising materials with potential applications in many fields including environment remediation [122]. 
Graphene structures, especially in the form of single- or multi-layer sheets, are advanced carbon-based materials with a broad range of applications including membrane separation for the desalination and water purification [123] as well using the graphene nanofillers and nanosheets for electronics industries [124]. They may be integrated also into a functional composite with metal-organic framework inducing better electrical conductivity, good thermal properties and chemical stability. Moreover, the incorporation of graphene nanosheets into these hybrid polymeric matrices enhances not only the electronic structure but also adjusts photothermal stability [125]. These advantages pave the way for the development of photocatalysts based on composites comprising graphene materials and MOF matrices. These graphene@MOF composites allow one to achieve enhanced $\mathrm{CO}_{2}$ photocatalytic reduction activity as compared to their pristine components [126].

Graphitic carbon nitride $\left(\mathrm{g}-\mathrm{C}_{3} \mathrm{~N}_{4}\right.$ ) has a layered structure similar to that of graphite, which is composed of graphene multi-layers, has a number of unique physicochemical properties due to the s-triazine cores. However, its electronic and electrochemical applications are limited by the relatively poor conductivity [127]. This hybrid carbon-based material has become a hot research topic in material science and energy conversion [81]. Its photocatalytic activity for visible light makes it a promising functional material for hydrogen evolution by water splitting and for pollutant degradation at room temperature [128]. In particular, it has been recognized as a catalyst for the photocatalytic $\mathrm{CO}_{2}$ reduction [129]. In photocatalytic $\mathrm{CO}_{2}$ reduction, a g- $\mathrm{C}_{3} \mathrm{~N}_{4}$ material shows appropriate conduction and valence bands, and the ability for visible-light adsorption [130]. Moreover, due to the favorable layer structure, graphitic carbon nitride can be integrated with other porous catalytic materials providing an advanced operation in $\mathrm{CO}_{2}$ reduction [131].

The BIF-20 boron imidazolate framework with a high density of $\mathrm{B}-\mathrm{H}$ bonds (see previous sections) was integrated with g- $\mathrm{C}_{3} \mathrm{~N}_{4}$ nanosheets via a facile electrostatic self-assembly approach under RT conditions, yielding a BIF-20@g- $\mathrm{C}_{3} \mathrm{~N}_{4}$ composite in a nanosheet form possessing a synergistic functionality [81]. The formation of the BIF-20@g- $\mathrm{C}_{3} \mathrm{~N}_{4}$ composite is shown in Figure 10. A reference composite (ZIF-8@g- $\mathrm{C}_{3} \mathrm{~N}_{4}$ ) with a similar architecture but without $\mathrm{B}-\mathrm{H}$ bonding (like in the BIF-20 structure) was also synthesized by integrating the ZIF-8 zeolitic imidazolate framework with graphitic carbon nitride nanosheet following a similar strategy.

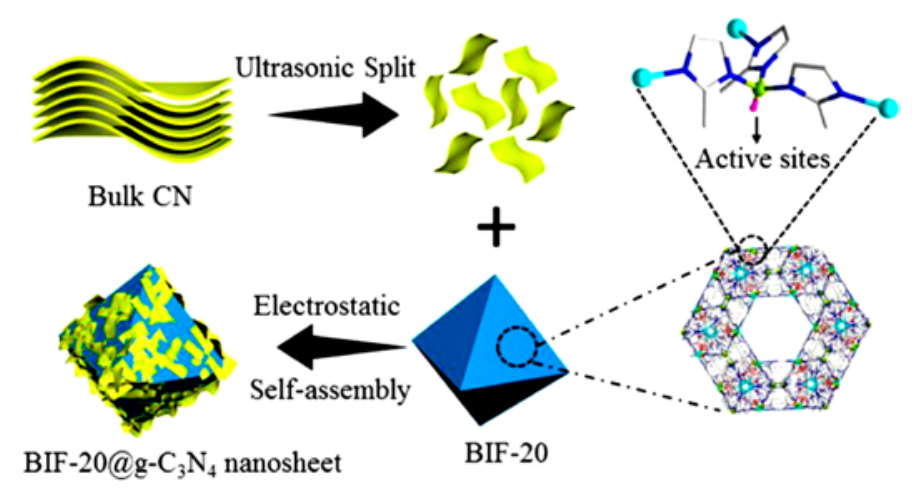

Figure 10. Schematic description of the preparation of the BIF-20@g- $\mathrm{C}_{3} \mathrm{~N}_{4}$ nanosheet photocatalyst. Reprinted with permission from [81].

The BIF-20@g- $\mathrm{C}_{3} \mathrm{~N}_{4}$ composite shows a high uptake value and selectivity for the $\mathrm{CO}_{2}$ adsorption (Table 2), which is necessary for the efficient photoreduction of carbon dioxide. Thus, this photocatalyst shows an enhanced performance in this reaction. In particular, the introduction of $\mathrm{B}-\mathrm{H}$ bonds into the photoreduction reaction system can not only generate efficient catalytic active sites but also enhance $\mathrm{CO}_{2}$ adsorption, thus realizing the activation of a $\mathrm{CO}_{2}$ molecule. The photogenerated excitations from the carbon nitride nanosheet can directionally migrate to $\mathrm{B}-\mathrm{H}$ bonding, thus preventing the electron-hole recombination in the $\mathrm{g}-\mathrm{C}_{3} \mathrm{~N}_{4}$ nanosheet and provides long-lived electrons for the reduction of adsorbed 
$\mathrm{CO}_{2}$. This cooperative action of the BIF-20@g- $\mathrm{C}_{3} \mathrm{~N}_{4}$ composite components boosts its photocatalytic $\mathrm{CO}_{2}$ conversion efficiency.

Noteworthy, the composite BIF-20@g- $\mathrm{C}_{3} \mathrm{~N}_{4}$ nanosheet shows a better $\mathrm{CO}_{2}$ uptake as compared to that of the reference ZIF-8@g- $\mathrm{C}_{3} \mathrm{~N}_{4}$ composite with the similar structure. This higher $\mathrm{CO}_{2}$ adsorption ability of the BIF-20@g- $\mathrm{C}_{3} \mathrm{~N}_{4}$ composite may be provided by a high density of B-H bonds homogeneously distributed in the BIF-20 framework. In addition, $\mathrm{B}-\mathrm{H}$ bonds can serve as trapping sites for $\mathrm{CO}_{2}$ adsorption, thus accelerating the kinetic process of $\mathrm{CO}_{2}$ adsorption.

The catalytic performance of the composite BIF-20@g- $\mathrm{C}_{3} \mathrm{~N}_{4}$ nanosheet was tuned by changing the g- $\mathrm{C}_{3} \mathrm{~N}_{4}$ content in it. In particular, the composite photocatalyst with $20 \mathrm{wt} . \% \mathrm{~g}-\mathrm{C}_{3} \mathrm{~N}_{4}$ loading shows the optimal catalytic performance, which is much better, i.e., $\mathrm{CH}_{4}$ evolution rate of $15.524 \mu \mathrm{mol} \mathrm{g}^{-1} \mathrm{~h}^{-1}$ (yield of $1.763 \mu \mathrm{mol}$ ) and CO evolution rate of $53.869 \mu \mathrm{mol} \mathrm{g}^{-1} \mathrm{~h}^{-1}$ (yield of $6.117 \mu \mathrm{mol}$ ), than that of the g- $\mathrm{C}_{3} \mathrm{~N}_{4}$ nanosheet (CO evolution rate of $5.407 \mu \mathrm{mol} \mathrm{g}^{-1} \mathrm{~h}^{-1}$ and $\mathrm{CH}_{4}$ evolution rate of $\left.1.549 \mu \mathrm{mol} \mathrm{g}^{-1} \mathrm{~h}^{-1}\right)$ and bulk-g- $\mathrm{C}_{3} \mathrm{~N}_{4}\left(\mathrm{CO}\right.$ evolution rate of $0.441 \mu \mathrm{mol} \mathrm{g}^{-1} \mathrm{~h}^{-1}$ and $\mathrm{CH}_{4}$ evolution rate of $0.113 \mu \mathrm{mol} \mathrm{g}^{-1} \mathrm{~h}^{-1}$ ). For the composite ZIF-8@g- $\mathrm{C}_{3} \mathrm{~N}_{4}$ nanosheet with the same content of $\mathrm{g}-\mathrm{C}_{3} \mathrm{~N}_{4}$ nanosheet $(20 \mathrm{wt} . \%)$, less efficient catalytic performance $\left(\mathrm{CH}_{4}\right.$ evolution rate of $3.386 \mu \mathrm{mol} \mathrm{g}^{-1} \mathrm{~h}^{-1}$ and CO evolution rate of $24.721 \mu \mathrm{mol} \mathrm{g}^{-1} \mathrm{~h}^{-1}$ ) was found.

The reported results show the superiority of the BIF-based composite catalysts in photocatalytic $\mathrm{CO}_{2}$ reduction as compared to both graphitic carbon nitride structures and other type zeolite-like materials, e.g., ZIF matrices.

\section{BIFs-Drived Materials}

\subsection{D BIFs-Derived Nanosheet Materials}

Along with OER, $\mathrm{CO}_{2} \mathrm{RR}$ is an important process from ecological point of view, which allows one to mitigate the negative environmental impact of carbon dioxide [51]. To date, the development of the efficient catalysts for $\mathrm{CO}_{2} \mathrm{RR}$ draws a significant attention in the global research community. As a result, a number of promising catalysts based on noble metals, such as $\mathrm{Au}$ and $\mathrm{Ag}$, and non-precious metals, i.e., $\mathrm{Fe}, \mathrm{Co}$, and $\mathrm{Ni}$, were prepared and studied [132,133]. During these investigations, it was established that increasing the exposure of active sites by transformation of bulk materials into corresponding ultrathin 2D nanosheets is an efficient strategy [97].

Ultrathin 2D materials have a number of unique properties allowing their advanced performance and enhanced efficiency as electrocatalysts, stimulating research toward methodologies that support their preparation. In particular, in addition to an increase of the reactivity and density of the active sites, enhancing the mass transfer through increasing the surface area, or growing the catalysts into 2D nanosheets with ultrathin thickness, could remarkably enhance the performance of OER catalysts. An example is producing iron-cobalt oxide nanosheets as efficient OER catalysts [97].

To date, there are only unique literature examples of the use of 2D nanosheets derived from MOF materials for the electrocatalytic application, i.e., OER and $\mathrm{CO}_{2} \mathrm{RR}$ [134]. The reason for this rare preparation of 2D ultrathin MOF-derived nanosheets for the electrocatalysis is an instability of many MOF structures with required intra- and inter-layer interactions under oxidation conditions. Moreover, most reported ultrathin MOF nanosheets were prepared by physical or chemical exfoliation of layered MOF matrices with redox-active metals like Fe. Atomically dispersed active metals may act not only as inorganic nodes (metal centers) in the metal-organic framework but also as the catalytically redox-active species [135]. During the electrocatalysis, the redox reactions involving these metal centers take place, which results in changing their coordination geometry.

In context, boron imidazolate frameworks may provide a promising platform for the development of $2 \mathrm{D}$ nanosheets for the OER and $\mathrm{CO}_{2} \mathrm{RR}$ processes due to high stability of at least a number of BIF structures in a broad range of $\mathrm{pH}$ values including strong alkaline media.

Very recently, an efficient strategy to prepare ultrathin 2D nanosheet derived from the boron imidazolate framework BIF-73 (Table 1), which may be utilized as a bifunctional OER and $\mathrm{CO}_{2} \mathrm{RR}$ 
catalyst [51]. The preparation and utilization of this electrocatalyst is shown in Figure 11. Note that BIF-73 shows an exceptional stability in a strong alkaline solution at a $\mathrm{pH}$ value of 14 for $12 \mathrm{~h}$. This chemical stability is unattainable for most reported MOF matrices including ZIF structures.

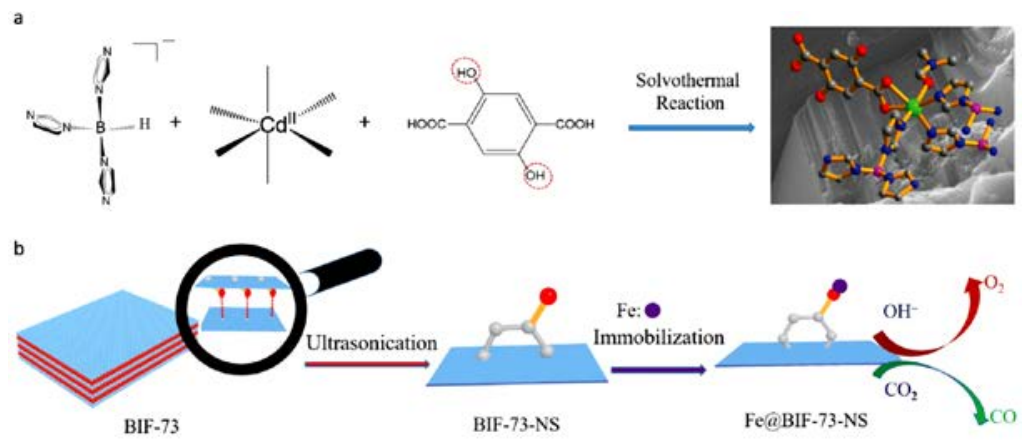

Figure 11. Schematic illustration of the BIF nanosheets for electrocatalytic application. (a) Scheme of the synthesis of BIF-73 (red circle: two potential functional OH groups, inset on the SEM of crystal: the coordination environment of BIF-73). (b) An ultrathin 2D BIF-73 nanosheets as the OER and $\mathrm{CO}_{2} \mathrm{RR}$ catalysis. The blue atom represents nitrogen, red atom represents oxygen, purple atom represents boron, grey atom represents carbon and green atom represents cadmium. Reprinted with permission from [51].

For the preparation of BIF-73-derived 2D nanosheets, a two-step strategy is used. It involves the synthesis of the BIF-73 material under solvothermal conditions. Then according to post-synthetic modification, the BIF-73 precursor is exfoliated using a liquid ultrasonication method to produce the nanosheet (BIF-73-NS). The structure of this crystalline material has common features with 2D double hydroxides (LDHs) and transition-metal dichalcogenides that are common catalysts for electrocatalysis [136]. As compared to these heterogeneous systems, the BIF-73-NS nanosheet catalyst also has a number of favorable physicochemical characteristics, i.e., the exposure of more ligand-based hydroxyl groups, enhanced conductivity and improved electrocatalytic activity due to appropriate active sites.

It is known that well dispersed and even better dispersed on the atomic level $\mathrm{Fe}^{3+}$ ions demonstrated superior faradaic efficiency (FE) for the electrochemical reduction of $\mathrm{CO}_{2}$ to $\mathrm{CO}$ [51]. Thus, for the further optimization of the electrocatalytic properties of the BIF-73-NS material in the OER and $\mathrm{CO}_{2} \mathrm{RR}$ processes, well-defined $\mathrm{Fe}_{2} \mathrm{O}_{3}$ subunits were incorporated in this host matrix by mixing with $\mathrm{Fe}^{3+}$ ions.

The hybrid Fe@BIF-73-NS electrocatalyst contains well dispersed ultra-small $\mathrm{Fe}_{2} \mathrm{O}_{3}$ fragments coordinated to the 2D BIF-73-NS matrix. This favorable structure results in an enhanced performance for the oxygen evolution reaction (OER: lower overpotential with $291 \mathrm{mV}$ at the current density of $10 \mathrm{~mA} \mathrm{~cm}^{-2}$ ) and carbon dioxide reduction reaction (faradaic efficiency of $\mathrm{CO}$ reaching $88.6 \%$ at $-1.8 \mathrm{~V}$ vs. $\mathrm{Ag} / \mathrm{AgCl}$ ). Both the theoretical calculations and electron microscopy study reveal that the superior OER performance of the Fe@BIF-73-NS electrocatalyst is provided by the increased exposure of the binding sites in the BIF-73-derived nanosheet coordinated with active $\mathrm{Fe}^{3+}$ centers.

Thus, this work provides an efficient strategy for the design of the 2D multifunctional nanosheets derived from BIF matrices with multipurpose applications for the energy conversion.

\subsection{BIFs-Derived Graphitic Materials}

An interesting example of the preparation of the graphitic-like material using boron imidazolate frameworks as precursors is the preparation of the porous borocarbonitride by the direct carbonization of BIF-36 matrix (Table 1) [47]. This BIF-36 borocarbonitride can be regarded as a multifunctional material with a number of potential application fields, i.e., it shows fast adsorption for 4-nitrophenol in the liquid phase and high temperature conductivity. 
In particular, the BIF-36-derived borocarbonitride demonstrates enhanced adsorption ability for toxic 4-nitrophenol in an aqueous solution under RT conditions. Using this graphitic-like matrix, the 4-nitrophenol adsorption was completed (99.99\%) in $5 \mathrm{~min}$.

Simultaneously, this borocarbonitride material can be used as a conductor at operation temperatures exceeding $300^{\circ} \mathrm{C}$. It was noted that the borocarbonitride material may act as a current switch due to rapid response-recovery time triggered by the temperature change.

\section{Conclusions and Perspectives}

At the end of this mini-review, we can compare two members of zeotype matrices, zeolitic imidazolate frameworks and boron imidazolate frameworks regarding the progress made in exploring both materials. ZIF structures were developed a bit earlier, namely three years earlier than the appearance of the BIF structures. However, the endeavors on the ZIFs materials made a significant progress than the researches related to the BIF materials. The library of the synthesized ZIF structures is much more numerous than those for boron imidazolate frameworks. It may be associated with significantly facile and available synthesis of the same ZIF materials allowing one to accomplish one-step syntheses under different conditions, such as solvothermal procedure, RT and ultrasoundand MW-assisted techniques. BIFs materials synthesis according to a two-step approach remains more sophisticated due to the necessity to prepare preliminary the boron imidazolate complexes serving as building blocks in the BIF structure self-assembly at the second stage.

As the other side of the coin, thanks to the same reason, BIF structures allow one a more predictable rational design with formation of much more precise target topologies and configurations. The authors suggest that there is an urgent need to place the BIF materials synthesis "from sky to earth" by extending the set of the available procedures for their preparation, because it is an obligatory condition for their successful practical exploitation. An important synthesis route is a $\mathrm{MW}$-assisted procedure as a promising way to control the crystal sizes and morphology of the BIF materials, which allows one simultaneously to reduce the reaction time. With this aspect, the need in the development of the simple and efficient synthesis routes for the boron imidazolate linkers with appropriate targeted functionality is associated. It should be pointed out that, in terms of the rational design, BIF structures have the advantage to combine the boron imidazolate linkers (that are needed by definition) with additional auxiliary linkers with another functionality, such as organic acids according to the important mixed linkers approach.

The considerations and analysis of the contemporary literature on boron imidazolate frameworks show that these zeolite-like metal-organic matrices may have promising applications in the modern fields, such as biomedicine, biorecognition (biosensing) and ecological areas, e.g., $\mathrm{CO}_{2}$ capture and reductive transformations into value-added products, energy conversion, drinking water remediation and detoxication. In this context, the increasingly efficient functional BIF materials with new unexplored properties are highly demanded. For this purpose, a deep study of the stability of the BIF matrices should be further performed.

However, the relevant literature inspection shows that many BIF structures demonstrate thermal stability up to $350-380^{\circ} \mathrm{C}$ under a $\mathrm{N}_{2}$ atmosphere, which is comparable or only a bit lower than reported for the ZIF matrices. This stability under heating conditions is sufficient for a number of practical exploitations of BIF materials. On the other hand, several the reported BIF materials retain their structural integrity in the aqueous solution. In this respect, boron imidazolate frameworks surpass ZIF matrices, which until recently have been recognized as exceptionally stable metal-organic frameworks. Actually, ZIF frameworks show good stability in a humid atmosphere. However, inconsistent results were reported about their stability in aqueous solutions. For instance, it was found that the famous ZIF-8 structure undergoes a phase shift to a substance with a crystalline, dense structure and a leaf-like morphology [137].

On the contrary, at least a few known BIF crystalline structures, such as BIF-89 and BIF-101, remain intact in a broad $\mathrm{pH}$ range, from strong acidic to highly alkaline ones. This favorable chemical 
stability could be associated with a number of structural characteristics of these zeotype matrices, the first being the presence of boron imidazolate linkers. The further enhancement of the chemical stability of the BIF structures may be provided by existence of two kinds of linkers in some boron imidazolate frameworks (such as BIF-91), i.e., boron imidazolate complexes and phenylene carboxylate ligands. Thus, the pending phenylene carboxylate linkers in the pores may increase the density of the coordination bonds and simultaneously act as rigid auxiliary linkers contributing to the excellent alkaline resistance of the BIF structures.

The fascinating capability of in situ fabrication of metal nanoparticles directly in the BIF matrices due to the reductive $\mathrm{BH}$ bonds in tripodal boron imidazolate linkers is well documented. Obviously, it paves the way to the functional or even multifunctional hybrid nanomaterials based on BIF structures. Despite the perspectivity, the fabrication of other types of BIF-based functional hybrids and composites remains almost unexplored. Thus, the preparation of these nanomaterials for multipurpose applications should be promoted. There is an urgent need to highlight more precisely the advantages of the functional materials based on BIF structures.

The authors believe that the studies in all these directions will open a new era in the rational design and possible practical exploitation of these fascinating zeolite-like materials.

Author Contributions: Conceptualization, L.M.K. and V.I.I.; software, K.E.P.; writing—original draft preparation, V.I.I. and K.E.P.; writing—review and editing, L.M.K.; supervision, L.M.K.; project administration, V.I.I. and L.M.K.; and funding acquisition, L.M.K. All authors have read and agreed to the published version of the manuscript.

Funding: This research was funded by RFBR, grant number 19-53-45032 in the part related to synthesis of BIFs and by Ministry of Science and Higher Education of the Russian Federation in the framework of Increase Competitiveness Program of NUST "MISiS" (grant Nos. K2-2019-005 and K4-2019-017) in the part related to application of BIFs.

Conflicts of Interest: The authors declare no conflict of interest.

\section{References}

1. Schuth, F.; Schmidt, W. Microporous and mesoporous materials. Adv. Mater. 2002, 14, 629-638. [CrossRef]

2. Li, J.; Corma, A.; Yu, J. Synthesis of new zeolite structures. Chem. Soc. Rev. 2015, 44, 7112-7127. [CrossRef]

3. Seoane, B.; Castellanos, S.; Dikhtiarenko, A.; Kapteijn, F.; Gascon, J. Multi-Scale Crystal Engineering of Metal Organic Frameworks. Coord. Chem. Rev. 2016, 307, 147-187. [CrossRef]

4. Eddaoudi, M.; Sava, D.F.; Eubank, J.F.; Adila, K.; Guillerma, V. Zeolite-like metal-organic frameworks (ZMOFs): Design, synthesis, and properties. Chem. Soc. Rev. 2015, 44, 228-249. [CrossRef] [PubMed]

5. Cheetham, K.; Ferey, G.; Loiseau, T. Angew. Chem. Int. Ed. 1999, 38, 3268-3292. [CrossRef]

6. Chen, B.; Yang, Z.; Zhu, Y.; Xia, Y. Zeolitic Imidazolate Framework Materials: Recent Progress in Synthesis and Applications. J. Mater. Chem. A 2014, 2, 16811-16831. [CrossRef]

7. Li, J.; Yu, J.; Xu, R. Progress in heteroatom-containing aluminophosphate molecular sieves. Proc. R. Soc. A 2012, 468, 1955-1967. [CrossRef]

8. Wilson, S.T.; Lok, B.M.; Messina, C.A.; Cannan, T.R.; Flanigen, E.M. Aluminophosphate molecular sieves: A new class of microporous crystalline inorganic solids. J. Am. Chem. Soc. 1982, 104, 1146-1147. [CrossRef]

9. Cora, F.; Alfredsson, M.; Barker, C.M.; Bell, R.G.; Foster, M.D.; Saadoune, I.; Simperler, A.; Catlow, C.R.A. Modeling the framework stability and catalytic activity of pure and transition metal-doped zeotypes. J. Solid State Chem. 2003, 176, 496-529. [CrossRef]

10. Hartmann, M.; Elangovan, S.P. Catalysis with Microporous Aluminophosphates and Silicoaluminophosphates Containing Transition Metals. In Advances in Nanoporous Materials; Ernst, S., Ed.; Elsevier: Amsterdam, The Netherlands, 2010; Volume 1, pp. 1-336.

11. Rowsell, J.L.C.; Yaghi, O.M. Metal-organic frameworks: A new class of porous materials. Microporous Mesoporous Mater. 2004, 73, 3-14. [CrossRef]

12. Férey, G. Hybrid porous solids: Past, present, future. Chem. Soc. Rev. 2008, 37, 191-214. [CrossRef] [PubMed]

13. Zhou, H.-C.; Long, G.; Yaghi, O.M. Introduction to Metal-Organic Frameworks. Chem. Rev. 2012, 112, 673-674. [CrossRef] [PubMed] 
14. Diercks, K.S.; Kalmutzki, M.G.; Diercks, N.G.; Yaghi, O.M. Conceptual Advances from Werner Complexes to Metal-Organic Frameworks. ACS Cent. Sci. 2018, 4, 1457-1464. [CrossRef] [PubMed]

15. Zhang, H.X.; Liu, M.; Wen, T.; Zhang, J. Synthetic design of functional boron imidazolate frameworks. Coord. Chem. Rev. 2016, 307, 255-266. [CrossRef]

16. Khay, I.; Chaplais, G.; Nouali, H.; Ortiz, G.; Marichal, C.; Patarin, J. Assessment of the Energetic Performances of Various ZIFs with SOD or RHO Topology Using High Pressure Water Intrusion-Extrusion Experiments. Dalton Trans. 2016, 45, 4392-4400. [CrossRef]

17. Tan, Y.-X.; Wang, F.; Zhang, J. Design and synthesis of multifunctional metal-organic zeolites. Chem. Soc. Rev. 2018, 47, 2130-2144. [CrossRef]

18. Corma, A. State of the art and future challenges of zeolites as catalysts. J. Catal. 2003, 216, 298-312. [CrossRef]

19. O'Keeffe, M.; Peskov, M.A.; Ramsden, S.J.; Yaghi, O.M. The Reticular Chemistry Structure Resource (RCSR) Database of, and Symbols for, Crystal Nets. Acc. Chem. Res. 2008, 41, 1782-1789. [CrossRef]

20. Bavykina, A.; Kolobov, N.; Khan, I.S.; Bau, J.A.; Ramirez, A.; Gascon, J. Metal-Organic Frameworks in Heterogeneous Catalysis: Recent Progress, New Trends, and Future Perspectives. Chem. Rev. 2020. [CrossRef]

21. Petit, C. Present and future of MOF research in the field of adsorption and molecular separation. Curr. Opin. Chem. Eng. 2018, 20, 132-142. [CrossRef]

22. Dhaka, S.; Kumar, R.; Deep, A.; Kurade, M.B.; Ji, S.W.; Jeon, B.H. Metal-organic frameworks (MOFs) for the removal of emerging contaminants from aquatic environments. Coord. Chem. Rev. 2019, 380, 330-352. [CrossRef]

23. Yang, Y.; Yang, Y.-W. Metal-Organic frameworks for biomedical applications. Small 2020. [CrossRef] [PubMed]

24. Wang, H.-S. Metal-organic frameworks for biosensing and bioimaging applications. Coord. Chem. Rev. 2017, 349, 139-155. [CrossRef]

25. Tian, Y.; Cai, C.; Ji, Y.; You, X.; Peng, S.; Lee, G. [Co $5(\mathrm{Im})_{\left.10 \_2 M B\right] \infty:}$ A Metal-Organic Open-Framework with Zeolite-Like Topology. Angew. Chem. Int. Ed. 2002, 41, 1384-1386. [CrossRef]

26. Noh, K.; Lee, J.; Kim, J. Compositions and Structures of Zeolitic Imidazolate Frameworks. Isr. J. Chem. 2018, 58, 1075-1088. [CrossRef]

27. Wu, T.; Bu, X.; Zhang, J.; Feng, P. New Zeolitic Imidazolate Frameworks: From Unprecedented Assembly of Cubic Clusters to Ordered Cooperative Organization of Complementary Ligands. Chem. Mater. 2008, 20, 7377-7382. [CrossRef]

28. Zhang, J.; Wu, T.; Zhou, C.; Chen, S.; Feng, P.; Bu, X. Zeolitic Boron Imidazolate Frameworks. Angezw. Chem. Int. Ed. 2009, 48, 2542-2545. [CrossRef]

29. Brekalo, I.; Deliz, D.E.; Kane, C.M.; Frišcic, T.; Holman, K.T. Templates in the Mechanochemical Synthesis of RHO Topology Zeolitic Imidazolate Frameworks (ZIFs). Molecules 2020, 25, 633. [CrossRef]

30. Moosavi, S.M.; Boyd, P.G.; Sarkisov, L.; Smit, B. Improving the Mechanical Stability of Metal-Organic Frameworks Using Chemical Caryatids. ACS Cent. Sci. 2018, 4, 832-839. [CrossRef]

31. Phan, A.; Doonan, C.J.; Uribe-Romo, F.J.; Knobler, C.B.; O'Keeffe, M.; Yaghi, O.M. Synthesis, Structure, and Carbon Dioxide Capture Properties of Zeolitic Imidazolate Frameworks. Acc. Chem. Res. 2010, 43, 58-67. [CrossRef]

32. Hayashi, H.; Cote, A.P.; Furukawa,H.; O’Keeffe, M.; Yaghi, O.M. Zeolite a imidazolate framework. Nat. Mater. 2007, 6, 501-506. [CrossRef] [PubMed]

33. Banerjee, R.; Phan, A.; Wang, B.; Knobler, C.; Furukawa, H.; O’Keeffe, M.; Yaghi, O.M. High-throughput synthesis of zeolitic imidazolate frameworks and application to $\mathrm{CO}_{2}$ capture. Science 2008, 319, 939-943. [CrossRef] [PubMed]

34. Kaneti, V.V.; Dutta, S.; Hossain, M.S.A.; Shiddiky, M.J.A.; Tung, K.-L.; Shieh, F.-K.; Tsung, C.-K.; Wu, K.C.-W.; Yamauchi, Y. Strategies for Improving the Functionality of Zeolitic Imidazolate Frameworks: Tailoring Nanoarchitectures for Functional Applications. Adv. Mater. 2017, 29, 1700213. [CrossRef]

35. Zhang, H.-X.; Fu, H.-R.; Li, H.-Y.; Zhang, J.; Bu, X. Porous ctn-Type Boron Imidazolate Framework for Gas Storage and Separation. Chem. Eur. J. 2013, 19, 11527-11530. [CrossRef]

36. Baburin, I.A.; Assfour, B.; Seifert, G.; Leoni, S. Polymorphs of lithium-boron imidazolates: Energy landscape and hydrogen storage properties. Dalton Trans. 2011, 40, 3796-3798. [CrossRef] 
37. Wang, F.; Shu, Y.-B.; Bu, X.; Zhang, J. Zeolitic Boron Imidazolate Frameworks with 4-Connected Octahedral Metal Centers. Chem. Eur. J. 2012, 18, 11876-11879. [CrossRef]

38. Nguyen, T.T.; Furukawa, H.; Gandara, F.; Nguyen, H.T.; Cordova, K.E.; Yaghi, O.M. Selective Capture of Carbon Dioxide under Humid Conditions by Hydrophobic Chabazite-Type Zeolitic Imidazolate Frameworks. Angew. Chem. Int. Ed. 2014, 53, 10645-10648. [CrossRef]

39. Jiang, J.; Zhao, Y.; Yaghi, O.M. Covalent Chemistry beyond Molecules. J. Am. Chem. Soc. 2016, 138, 3255-3265. [CrossRef]

40. Wen, T.; Zheng, Y.; Zhang, J.; Davey, K.; Qiao, S.-Z. Co (II) Boron Imidazolate Framework with Rigid Auxiliary Linkers for Stable Electrocatalytic Oxygen Evolution Reaction. Adv. Sci. 2019, 6, 1801920. [CrossRef]

41. Zhang, H.-X.; Wang, F.; Yang, H.; Tan, Y.X.; Zhang, J.; Bu, X. Interrupted Zeolite LTA and ATN-Type Boron Imidazolate Frameworks. J. Am. Chem. Soc. 2011, 133, 11884-11887. [CrossRef]

42. Zhang, H.-X.; Liu, M.; Xu, G.; Liu, L.; Zhang, J. Selectivity of $\mathrm{CO}_{2}$ via Pore Space Partition in Zeolitic Boron Imidazolate Frameworks. Chem. Commun. 2016, 52, 3552-3555. [CrossRef]

43. Zhang, D.-X.; Zhang, H.-X.; Wen, T.; Li, D.-S.; Zhang, J. Mechanochromic Cu(I) Boron Imidazolate Frameworks with Low-dimensional Structures and Reducing Function. Inorg. Chem. Front. 2016, 3, 263-267. [CrossRef]

44. Wen, T.; Zhang, J. Rational design of metal boron imidazolate cages to frameworks. Inorg. Chim. Acta 2017, 460, 89-92. [CrossRef]

45. Zhang, H.-X.; Hong, Q.-L.; Li, J.; Wang, F.; Huang, X.; Chen, S.; Tu, W.; Yu, D.; Xu, R.; Zhou, T.; et al. Isolated Square-Planar Copper Center in Boron Imidazolate Nanocages for Photocatalytic Reduction of $\mathrm{CO}_{2}$ to $\mathrm{CO}$. Angew. Chem. Int. Ed. 2019, 58, 11752-11756. [CrossRef]

46. Wen, T.; Zhang, D.-X.; Zhang, H.-X.; Zhang, H.-B.; Zhang, J.; Li, D.-S. Redox-active Cu(I) boron imidazolate framework for mechanochromic and catalytic applications. Chem. Commun. 2014, 50, 8754-8756. [CrossRef] [PubMed]

47. Wen, T.; Chen, E.-X.; Zhang, D.-X.; Zhang, J. Synthesis of borocarbonitride from a multifunctional Cu(I) boron imidazolate framework. Dalton Trans. 2016, 45, 5223-5228. [CrossRef]

48. Wen, T.; Zhang, D.X.; Liu, J.; Zhang, H.X.; Zhang, J. Facile synthesis of bimetal Au-Ag nanoparticles in a $\mathrm{Cu}(\mathrm{I})$ boron imidazolate framework with mechanochromic properties. Chem. Commun. 2015, 51, 1353-1355. [CrossRef]

49. Zhang, D.-X.; Liu, J.; Zhang, H.-X.; Wen, T.; Zhang, J. A Rational Strategy to Construct a Neutral Boron Imidazolate Framework with Encapsulated Small-Size Au-Pd Nanoparticles for Catalysis. Inorg. Chem. 2015, 54, 6069-6071. [CrossRef]

50. Liu, L.; Wen, T.; Chen, S.; Zhang, J. A zeolitic Cd (II) boron imidazolate framework with sensing and catalytic properties. J. Solid State Chem. 2015, 231, 185-189. [CrossRef]

51. Wen, T.; Liu, M.; Chen, S.; Li, Q.; Du, Y.; Zhou, T.; Ritchie, C.; Zhang, J. 2D Boron Imidazolate Framework Nanosheets with Electrocatalytic Applications for Oxygen Evolution and Carbon Dioxide Reduction Reaction. Small 2020, 1907669. [CrossRef]

52. Liu, M.; Zhang, D.-X.; Chen, S.; Wen, T. Loading Ag nanoparticles on Cd II boron imidazolate framework for photocatalysis. J. Solid State Chem. 2016, 237, 32-35. [CrossRef]

53. Liu, M.; Chen, S.; Wen, T.; Zhang, J. Encapsulation of Ln (III) ions/Ag nanoparticles within Cd (II) boron imidazolate frameworks for tuning luminescence emission. Chem. Commun. 2016, 52, 8577-8580. [CrossRef] [PubMed]

54. Wen, T.; Zheng, Y.; Xu, C.C.; Zhang, J.; Jaroniec, M.; Qiao, S.Z. A boron imidazolate framework with mechanochromic and electrocatalytic properties. Mater. Horiz. 2018, 5, 1151-1155. [CrossRef]

55. Hong, Q.-L.; Zhang, H.-X.; Zhang, J. Synthesis of boron imidazolate frameworks with cobalt clusters for efficient visible-light driven $\mathrm{CO}_{2}$ reduction. J. Mater. Chem. A 2019, 7, 17272-17276. [CrossRef]

56. Qia, Y.; Yea, J.; Ren, S.; Lva, J.; Zhang, S.; Che, Y.; Ning, G. In-situ synthesis of metal nanoparticles@metal-organic frameworks: Highly effective catalytic performance and synergistic antimicrobial activity. J. Hazard. Mater. 2020, 387, 121687. [CrossRef] [PubMed]

57. De Azevedo, D.C.S.; Cardoso, D.; Fraga, M.A.; Pastore, H.O. Zeolites for a Sustainable World. Microporous Mesoporous Mater. 2017, 254, 1-2. [CrossRef]

58. Newsam, J.M. The Zeolite Cage Structure. Science 1986, 231, 1093-1099. [CrossRef]

59. Hong, Q.-L.; Zhang, H.-X.; Wen, Y.-H.; Zhang, J. One unique neutral boron imidazolate framework with fluorescent property. Inorg. Chem. Commun. 2018, 95, 130-133. [CrossRef] 
60. Lu, Z.; Knobler, C.B.; Furukawa, H.; Wang, B.; Liu, G.; Yaghi, O.M. Synthesis and Structure of Chemically Stable Metal-Organic Polyhedra. J. Am. Chem. Soc. 2009, 131, 12532-12533. [CrossRef]

61. Furukawa, H.; Kim, J.; Plass, K.E.; Yaghi, O.M. Crystal Structure, Dissolution, and Deposition of a $5 \mathrm{~nm}$ Functionalized Metal-Organic Great Rhombicuboctahedron. J. Am. Chem. Soc. 2006, 128, 8398-8399. [CrossRef]

62. Zhang, G.; Mastalerz, M. Organic cage compounds-from shape-persistency to function. Chem. Soc. Rev. 2014, 43, 1934-1947. [CrossRef] [PubMed]

63. Rostamnia, S.; Karimi, Z. Preparation and catalytically study of metal-organic frameworks of amine/MIL-53 (Al) as a powerful option in the rapid $N$-formylation condensation in neat conditions. Inorg. Chim. Acta 2015, 428, 133. [CrossRef]

64. Rostamnia, S.; Alamgholiloo, H.; Liu, X. Pd-grafted open metal site copper-benzene-1,4-dicarboxylate metal organic frameworks (Cu-BDC MOF's) as promising interfacial catalysts for sustainable Suzuki coupling. J. Colloid Interface Sci. 2016, 46, 310-317. [CrossRef]

65. Lee, J.; Kwak, H.J.; Choe, W. Evolution of form in metal-organic frameworks. Nat. Commun. 2017, 8, 14070. [CrossRef]

66. Zhang, D.-X.; Zhang, H.-X.; Li, H.-Y.; Wen, T.; Zhang, J. Targeted design of a cubic boron imidazolate cage with sensing and reducing functions. Dalton Trans. 2015, 44, 9367-9369. [CrossRef]

67. Zhang, D.X.; Zhang, H.X.; Li, H.Y.; Wen, T.; Zhang, J. Self-Assembly of Metal Boron Imidazolate Cages. Cryst. Growth Des. 2015, 15, 2433-2436. [CrossRef]

68. Ramirez, J.R.; Yang, H.; Kane, C.M.; Ley, A.N.; Holman, K.T. Reproducible Synthesis and High Porosity of Mer-Zn(Im) 2 (ZIF-10): Exploitation of an Apparent Double-Eight Ring Template. J. Am. Chem. Soc. 2016, 138, 12017-12020. [CrossRef] [PubMed]

69. Frišcic, T.; Halasz, I.; Beldon, P.J.; Belenguer, A.M.; Adams, F.; Kimber, S.A.J.; Honkimäki, V.; Dinnebier, R.E. Real-Time and in Situ Monitoring of Mechanochemical Milling Reactions. Nat. Chem. 2013, 5, 66-73. [CrossRef] [PubMed]

70. Jeazet, H.B.T.; Staudt, C.; Janiak, C. Metal-organic frameworks in mixed-matrix membranes for gas separation. Dalton Trans. 2012, 41, 14003-14027. [CrossRef]

71. Gangu, K.K.; Maddila, S.; Mukkamala, S.B.; Jonnalagadda, S.B. A review on contemporary Metal-Organic Framework materials. Inorg. Chim. Acta 2016, 446, 61-74. [CrossRef]

72. Isaeva, V.I.; Barkova, M.I.; Kustov, L.M.; Syrtsova, D.A.; Efimova, E.A.; Teplyakov, V.V. In Situ synthesis of novel ZIF-8 membranes on polymeric and inorganic supports. J. Mater. Chem. A. 2015, 3, 7469-7476. [CrossRef]

73. Hillman, F.; Heong, H.-K. Linker-Doped Zeolitic Imidazolate Frameworks (ZIFs) and Their Ultrathin Membranes for Tunable Gas Separations. ACS Appl. Mater. Interfaces. 2019, 11, 18377-18385. [CrossRef] [PubMed]

74. Noguera-Díaz, A.; Villarroel-Rocha, J.; Ting, V.P.; Bimbo, N.; Sapag, K.; Mays, T.J. Flexible ZIFs: Probing guest-induced flexibility with $\mathrm{CO}_{2}, \mathrm{~N}_{2}$ and Ar adsorption. J. Chem. Technol. Biotechnol. 2019, 94, 3787-3792. [CrossRef]

75. Stepanov, A.V.; Mel'nik, C.E.; Isaeva, V.I.; Kapustin, G.I.; Chernyshev, V.V.; Veselovsky, V.V. The Henry reaction catalyzed by zeolitic imidazolate framework ZIF-8. Mend. Commun. 2018, 28, 88-90. [CrossRef]

76. Carraro, F.; Velásquez-Hernández, M.D.J.; Astria, E.; Liang, W.; Twight, L.; Parise, C.; Ge, M.; Huang, Z.; Ricco, R.; Zou, X.; et al. Phase dependent encapsulation and release profile of ZIF-based biocomposites. Chem. Sci. 2020, 11, 3397-3404. [CrossRef]

77. Zhang, H.-X.; Liu, M.; Bu, X.; Zhang, J. Zeolitic BIF Crystal Directly Producing Noble-Metal Nanoparticles in Its Pores for Catalysis. Sci. Rep. 2014, 4, 3923. [CrossRef] [PubMed]

78. Pham, T.; Forrest, K.A.; Furukawa, H.; Eckert, J.; Space, B. Hydrogen Adsorption in a Zeolitic Imidazolate Framework with lta Topology. J. Phys. Chem. C 2018, 122, 15435-15445. [CrossRef]

79. Tang, Y.-H.; Wang, F.; Liu, J.-X.; Zhang, J. Diverse tetrahedral tetrazolate frameworks with N-rich surface. Chem. Commun. 2016, 52, 5625-5628. [CrossRef]

80. D'Alessandro, D.M.; Smit, B.; Long, J.R. Carbon Dioxide Capture: Prospects for New Materials. Angew. Chem. Int. Ed. 2010, 49, 6058-6082. [CrossRef] 
81. Xu, G.; Zhang, H.; Wei, J.; Zhang, H.-X.; Wu, X.; Li, Y.; Li, C.; Zhang, J.; Ye, J. Integrating the g-C3N4 Nanosheet with B-H Bonding Decorated Metal-Organic Framework for $\mathrm{CO}_{2}$ Activation and Photoreduction. ACS Nano 2018, 12, 5333-5340. [CrossRef]

82. He, Y.; Zhang, Z.; Xiang, S.; Fronczek, F.R.; Krishna, R.; Chen, B. A robust doubly interpenetrated metal-organic framework constructed from a novel aromatic tricarboxylate for highly selective separation of small hydrocarbons. Chem. Commun. 2012, 48, 6493-6495. [CrossRef] [PubMed]

83. Gao, S.; Morris, C.G.; Lu, Z.; Yan, Y.; Godfrey, H.G.W.; Murray, C.; Tang, C.C.; Thomas, S.; Yang, K.M.; Schröder, M. Selective Hysteretic Sorption of Light Hydrocarbons in a Flexible Metal-Organic Framework Material. Chem. Mater. 2016, 28, 2331-2340. [CrossRef]

84. Tan, L.-L.; Li, H.; Qiu, Y.-C.; Chen, D.-X.; Wang, X.; Pan, R.-Y.; Wang, Y.; Zhang, S.X.-A.; Wang, B.; Yang, Y.-W. Stimuli-responsive metal-organic frameworks gated by pillar [5] arene supramolecular switches. Chem. Sci. 2015, 6, 1640-1644. [CrossRef] [PubMed]

85. Knebel, A.; Zhou, C.; Huang, A.; Zhang, J.; Kustov, L.; Caro, J. Smart Metal-Organic Frameworks (MOFs): Switching Gas Permeation through MOF Membranes by External Stimuli Smart Metal-Organic Frameworks (MOFs): Switching Gas Permeation through MOF Membranes by External Stimuli. Chem. Eng. Technol. 2018, 41, 224-234. [CrossRef]

86. Zheng, G.; de Marchi, S.; Llpez-Puente, V.; Sentosun, K.; Polavarapu, L.; Perez-Juste, I.; Hill, S.; Bals, E.H.; Liz-Marzan, L.M.; Pastoriza-Santos, I.; et al. Encapsulation of Single Plasmonic Nanoparticles within ZIF-8 and SERS Analysis of the MOF Flexibility. Small 2016, 12, 3935-3943. [CrossRef]

87. Hu, P.; Morabito, J.V.; Tsung, C.-K. Core-Shell Catalysts of Metal Nanoparticle Core and Metal-Organic Framework. Shell ACS Catal. 2014, 4, 4409-4419. [CrossRef]

88. Zhu, Q.L.; Shen, C.J.; Tan, C.H.; Sheng, T.L.; Hu, S.M.; Wu, X.T. Bright blue emissions with temperature-dependent quantum yields from microporous metal-organic frameworks. Chem. Commun. 2012, 48, 531-533. [CrossRef]

89. Rocha, J.; Carlos, L.D.; Paz, F.A.A.; Ananias, D. Luminescent multifunctional lanthanides-based metal-organic frameworks. Chem. Soc. Rev. 2011, 40, 926-940. [CrossRef]

90. Vikrant, K.; Giri, B.S.; Raza, N.; Roy, K.; Kim, K.H.; Rai, B.N.; Singh, R.S. Recent advancements in bioremediation of dye: Current status and challenges. Bioresour. Technol. 2018, 253, 355-367. [CrossRef]

91. Bedia, J.; Muelas-Ramos, V.; Peñas-Garzón, M.; Gómez-Avilés, A.; Rodríguez, J.J.; Belver, C. A Review of Photocatalytic Water Purification with Metal Organic Frameworks. Catalysts 2019, 19, 52. [CrossRef]

92. Dhakshinamoorthy, A.; Li, Z.; Garcia, H. Catalysis and photocatalysis by metal organic frameworks. Chem. Soc. Rev. 2018, 47, 8134-8172. [CrossRef] [PubMed]

93. Alkhati, I.I.; Garlisi, C.; Pagliaro, M.; Al-Ali, K.; Palmisano, G. Metal-organic frameworks for photocatalytic $\mathrm{CO}_{2}$ reduction under visible radiation: A review of strategies and applications. Catal. Today 2020, 340, 209-224. [CrossRef]

94. Sibo, W.; Wangshu, Y.; Jinliang, L.; Zhengxin, D.; Xinchen, W. Cobalt imidazolate metal-organic frameworks photosplit $\mathrm{CO}_{2}$ under mild reaction conditions. Angew. Chem. Int. Ed. 2014, 53, 1034-1038.

95. Wang, S.; Lin, J.; Wang, X. Semiconductor-redox catalysis promoted by metal-organic frameworks for $\mathrm{CO}_{2}$ reduction. J. Chem. Soc. Faraday Trans. 2014, 16, 14656-14660. [CrossRef]

96. Martínez-Vargas, D.X.; Sandoval-Rangel, L.; Campuzano-Calderon, O.; Romero-Flores, M.; Lozano, F.J.; Nigam, K.D.P.; Mendoza, A. Montesinos-Castellanos. Recent Advances in Bifunctional Catalysts for the Fischer-Tropsch Process: One-Stage Production of Liquid Hydrocarbons from Syngas A. Ind. Eng. Chem. Res. 2019, 58, 15872-15901. [CrossRef]

97. Zhuang, L.; Ge, L.; Yang, Y.; Li, M.; Jia, Y.; Yao, X.; Zhu, Z. Ultrathin Iron-Cobalt Oxide Nanosheets with Abundant Oxygen Vacancies for the Oxygen Evolution Reaction. Adv. Mater. 2017, 29, 1606793. [CrossRef]

98. Dou, S.; Li, X.Y.; Tao, L.; Huo, J.; Wang, S.Y. Cobalt nanoparticle-embedded carbon nanotube/porous carbon hybrid derived from MOF-encapsulated $\mathrm{Co}_{3} \mathrm{O}_{4}$ for oxygen electrocatalysis. Chem. Commun. 2016, 52, 9727-9730. [CrossRef]

99. Song, F.; Hu, X.L. Exfoliation of layered double hydroxides for enhanced oxygen evolution catalysis. Nat. Commun. 2014, 5, 4477. [CrossRef]

100. Rincon, R.A.; Ventosa, E.; Tietz, F.; Masa, J.; Seisel, S.; Kuznetsov, V.; Schuhmann, W. Evaluation of Perovskites as Electrocatalysts for the Oxygen Evolution Reaction. ChemPhysChem 2014, 15, 2810-2816. [CrossRef] 
101. Ding, M.; Cai, X.; Jiang, H.-L. Improving MOF stability: Approaches and applications. Chem. Sci. 2019, 10, 10209-10230. [CrossRef]

102. Wu, H.B.; Lou, X.W. Metal-organic frameworks and their derived materials for electrochemical energy storage and conversion: Promises and challenges. Sci. Adv. 2017, 3, eaap9252. [CrossRef] [PubMed]

103. Li, F.L.; Shao, Q.; Huang, X.; Lang, J.P. Nanoscale Trimetallic Metal-Organic Frameworks Enable Efficient Oxygen Evolution Electrocatalysis. Angew. Chem. Int. Ed. 2018, 57, 1888-1892. [CrossRef] [PubMed]

104. Gao, X.; Liu, J.; Sun, Y.; Wang, X.; Geng, Z.; Shi, F.; Wang, X.; Zhang, W.; Feng, S.; Wang, Y.; et al. Optimized $\mathrm{Co}^{2+}(\mathrm{Td})-\mathrm{O}-\mathrm{Fe}^{3+}(\mathrm{Oh})$ electronic states in a spinel electrocatalyst for highly efficient oxygen evolution reaction performance. Inorg. Chem. Front. 2019, 6, 3295-3301. [CrossRef]

105. Grosu, Y.; Gomes, S.; Renaudin, G.; Grolier, J.P.E.; Eroshenko, V.; Nedelec, J.M. Stability of zeolitic imidazolate frameworks: Effect of forced water intrusion and framework flexibility dynamics. RSC Adv. 2015, 5, 89498-89502. [CrossRef]

106. Chen, L.; Xu, Q. Metal-Organic Framework Composites for Catalysis. Matter 2019, 1, 57-89. [CrossRef]

107. Falcaro, P.; Ricco, R.; Yazdi, A.; Imaz, I.; Furukawa, S.; Maspoch, D.; Ameloot, R.; Evans, J.D.; Doonan, C.J. Application of Metal and Metal Oxide Nanoparticles@MOFs. Coord. Chem. Rev. 2016, 307, 237-254. [CrossRef]

108. Moon, H.R.; Limb, D.-W.; Suh, M.P. Fabrication of metal nanoparticles in metal-organic frameworks. Chem. Soc. Rev. 2013, 42, 1807-1824. [CrossRef]

109. Yu, J.; Mu, C.; Yan, B.; Qin, X.; Shen, C.; Xue, H.; Pang, H. Nanoparticle/MOF composites: Preparations and applications. Mater. Horiz. 2017, 4, 557-569. [CrossRef]

110. Rösler, C.; Fischer, R.A. Metal-organic frameworks as hosts for nanoparticles. CrystEngComm 2015, 17, 199-217. [CrossRef]

111. Isaeva, V.I.; Eliseev, O.L.; Chernyshev, V.V.; Bondarenko, T.N.; Vergun, V.V.; Kapustin, G.I.; Lapidus, A.L.; Kustov, L.M. Palladium nanoparticles embedded in MOF matrices: Catalytic activity and structural stability in iodobenzene methoxycarbonylation. Polyhedron 2019, 158, 55-64. [CrossRef]

112. Isaeva, V.I.; Eliseev, O.L.; Kazantsev, R.V.; Chernyshev, V.V.; Tarasov, A.L.; Davydov, P.E.; Lapidus, A.L.; Kustov, L.M. Effect of the support morphology on the performance of Co nanoparticles deposited on metal-organic framework MIL-53(Al) in Fischer-Tropsch synthesis. Polyhedron 2019, 157, 389-395. [CrossRef]

113. Stakheev, A.Y.; Isaeva, V.I.; Markov, P.V.; Turova, O.V.; Mashkovskii, I.S.; Kapustin, G.I.; Saifutdinov, B.R.; Kustov, L.M. Novel catalysts for selective hydrogenation of CC triple bond based on Pd nanoparticles immobilized in phenylenecarboxylate frameworks $\left(\mathrm{NH}_{2}\right) \mathrm{MIL}-53(\mathrm{Al})$. Russ. Chem. Bull. Int. Ed. 2015, 64, 284-290. [CrossRef]

114. Isaeva, V.I.; Prokudina, N.I.; Kozlova, L.M.; Kustov, L.M.; Glukhov, L.M.; Tarasov, A.L.; Beletskaya, I.P. Hydroamination of phenylacetylene in the presence of gold-containing catalytic systems supported on carriers modified by ionic liquids. Russ. Chem. Bull. Int. Ed. 2015, 64, 2811-2815. [CrossRef]

115. Belyaeva, E.V.; Isaeva, V.I.; Said-Galiev, E.E.; Tkachenko, O.P.; Savilov, S.V.; Egorov, A.V.; Kozlova, L.M.; Sharf, V.Z.; Kustov, L.M. New method for catalyst preparation based on metal-organic framework MOF-5 for the partial hydrogenation of phenylacetylene. Russ. Chem. Bull. Int. Ed. 2014, 63, 396-403. [CrossRef]

116. Cheon, Y.E.; Suh, M.P. Enhanced hydrogen storage by palladium nanoparticles fabricated in a redox-active metal-organic framework. Angew. Chem. Int. Ed. 2009, 48, 2899-2903. [CrossRef]

117. Xiong, Y.Y.; Li, J.Q.; Yan, C.S.; Gao, H.Y.; Zhou, J.P.; Gong, L.L.; Luo, M.B.; Zhang, L.; Meng, P.P.; Luo, F. MOF catalysis of Fe-II-to-Fe-III reaction for an ultrafast and one-step generation of the Fe2O3@MOF composite and uranium(VI) reduction by iron (II) under ambient conditions. Chem. Commun. 2016, 52, 9538-9541. [CrossRef] [PubMed]

118. Deng, Y.; Cai, Y.; Sun, Z.; Liu, J.; Liu, C.; Wei, J.; Li, W.; Liu, C.; Wang, Y.; Zhao, D. Multifunctional mesoporous composite microspheres with well designed nanostructure: A highly integrated catalyst system. J. Am. Chem. Soc. 2010, 132, 8466-8473. [CrossRef] [PubMed]

119. Duan, M.; Jiang, L.; Zeng, G.; Wang, D.; Tang, W.; Liang, J.; Wang, H.; He, D.; Liu, Z.; Tang, L. Bimetallic nanoparticles/metal-organic frameworks: Synthesis, applications and challenges. Appl. Mater. Today 2020, 19, 100564. [CrossRef]

120. Tate, G.; Kenvin, A.; Diao, W.; Monnier, J.R. Preparation of Pt-containing bimetallic and trimetallic catalysts using continuous electroless deposition methods. Catal. Today 2019, 334, 113-121. [CrossRef] 
121. Liu, X.-W.; Sun, T.-J.; Hu, J.-L.; Wang, S.-D. Composites of metal-organic frameworks and carbon-based materials: Preparations, functionalities and applications. J. Mater. Chem. A 2016, 4, 3584-3616. [CrossRef]

122. Zhu, L.; Meng, L.; Shi, J. Metal-organic frameworks/carbon-based materials for environmental remediation: State-of-the-art mini-review. J. Environ. Manag. 2019, 232, 964-977. [CrossRef]

123. Abdol, A.M.; Sadeghazadeh, S.; Jalaly, M.; Khatibi, M.M. Constructing a three-dimensional graphene structure via bonding layers by ion beam irradiation. Sci. Rep. 2019, 9, 8127. [CrossRef] [PubMed]

124. Paszkiewicz, S.; Szymczyk, A.; Sui, X.; Wagner, H.; Linares, A.; Ezquerra, T.A.; Rosłaniec, Z. Synergetic effect of single-walled carbon nanotubes (SWCNT) and graphene nanoplatelets (GNP) in electrically conductive PTT-block-PTMO hybrid nanocomposites prepared by in situ polymerization. Compos. Sci. Technol. 2015, 118, 72-77. [CrossRef]

125. Prolongo, S.; Redondo, O.; Campo, M.; Ureña, A. Heat dissipation on electrical conductor composites by combination of carbon nanotubes and graphene nanoplatelets. J. Coat. Technol. Res. 2019, 16, 491-498. [CrossRef]

126. Kidanemariam, A.; Lee, J.; Park, J. Recent Innovation of Metal-Organic Frameworks for Carbon Dioxide Photocatalytic Reduction. Polymers 2019, 11, 2090. [CrossRef]

127. Wang, X.; Maeda, K.; Thomas, A.; Takanabe, K.; Xin, G.; Carlsson, J.M.; Domen, K.; Antonietti, M. A Metal-free Polymeric Photocatalyst for Hydrogen Production from Water under Visible Light. Nat. Mater. 2009, 8, 76-80. [CrossRef]

128. Ingaki, M.; Tsumura, T.; Kinumoto, T.; Toyoda, M. Graphitic carbon nitrides (g-C3N4) with comparative discussion to carbon materials. Carbon 2019, 141, 580-607. [CrossRef]

129. Shi, L.; Wang, T.; Zhang, H.; Chang, K.; Ye, J. Electrostatic Self-Assembly of Nanosized Carbon Nitride Nanosheet onto a Zirconium Metal-Organic Framework for Enhanced Photocatalytic $\mathrm{CO}_{2}$ Reduction. Adv. Funct. Mater. 2015, 25, 5360-5367. [CrossRef]

130. Wang, R.; Gu, L.N.; Zhou, J.J.; Liu, X.L.; Teng, F.; Li, C.H.; Shen, Y.H.; Yuan, Y.P. Quasi-Polymeric Metal-Organic Framework UiO-66/g-C3N4, Heterojunctions for Enhanced Photocatalytic Hydrogen Evolution under Visible Light Irradiation. Adv. Mater. Interfaces 2015, 2, 1500037. [CrossRef]

131. Wang, H.; Yuan, X.; Wu, Y.; Zeng, G.; Chen, X.; Leng, L.; Li, H. Synthesis and Applications of Novel Graphitic Carbon Nitride/Metal-Organic Frameworks Mesoporous Photocatalyst for Dyes Removal. Appl. Catal. B 2015, 174, 445-454. [CrossRef]

132. Su, P.; Iwase, K.; Nakanishi, S.; Hashimoto, K.; Kamiya, K. Nickel-Nitrogen-Modified Graphene: An Efficient Electrocatalyst for the Reduction of Carbon Dioxide to Carbon Monoxide. Small 2016, 12, 6083-6089. [CrossRef] [PubMed]

133. Wang, X.; Chen, Z.; Zhao, X.; Yao, T.; Chen, W.; You, R.; Zhao, C.; Wu, G.; Wang, J.; Huang, W.; et al. Regulation of Coordination Number Over Single Co Sites: Triggering the Efficient Electroreduction of $\mathrm{CO}_{2}$. Angew. Chem. Int. Ed. 2018, 57, 1944-1948. [CrossRef]

134. Zhao, M.; Huang, Y.; Peng, Y.; Huang, Z.; Ma, Q.; Zhang, H. Two-dimensional metal-organic framework nanosheets: Synthesis and applications. Chem. Soc. Rev. 2018, 47, 6267-6295. [CrossRef]

135. Zhao, S.; Wang, Y.; Dong, J.; He, C.-T.; Yin, H.; An, P.; Zhao, K.; Zhang, X.; Gao, C.; Zhang, L.; et al. Ultrathin metal-organic framework nanosheets for electrocatalytic oxygen evolution. Nat. Energy 2016, 1, 16184. [CrossRef]

136. Wang, Y.; Zhang, Y.; Liu, Z.; Xie, C.; Feng, S.; Liu, D.; Shao, M.; Wang, S. Layered Double Hydroxide Nanosheets with Multiple Vacancies Obtained by Dry Exfoliation as Highly Efficient Oxygen Evolution Electrocatalysts. Angew. Chem. Int. Ed. 2017, 56, 5867-5871. [CrossRef] [PubMed]

137. Zhang, H.; Zhao, M.; Lin, Y.S. Stability of ZIF-8 in water under ambient conditions. Microporous Mesoporous Mater. 2019, 279, 201-210. [CrossRef]

(C) 2020 by the authors. Licensee MDPI, Basel, Switzerland. This article is an open access article distributed under the terms and conditions of the Creative Commons Attribution (CC BY) license (http://creativecommons.org/licenses/by/4.0/). 